Application of the Complex Equilibrium Code QUIL to Cesium-Impurity Equilibria in the Primary Coolant of High-Temperature Gas-Cooled Reactors

Issued: October 1976

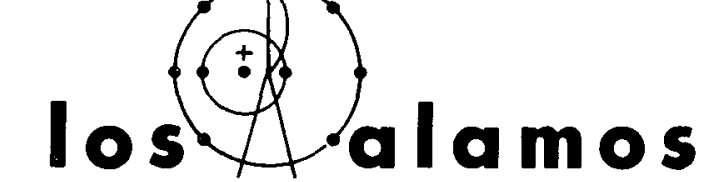

scientific laboratory

of the University of California

LOS ALAMOS, NEW MEXICO 87545

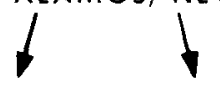

An Affirmative Action/Equal Opportunity Employer 
This work was performed under the auspices of the U.S. Nuclear Regulatory Commission's Office of Nuclear Regulatory Research, Division of Reactor Safety Research.

\author{
Printed in the United States of America. Available from \\ National Technical Information Service \\ U.S. Department of Commerce \\ 5285 Port Royal Road \\ Springfield, VA 22161 \\ Price: Printed Copy $\$ 4.00$ Microfiche $\$ 2.25$
}

NOTICE

This report was prepared as an account of work sponsored by the United States Government. Neither the United States nor the United States Nuclear Regulatory Commission, nor any of their employees, nor any of their contractors, subcontractors, or their employees, makes any warranty, express or implied, or assumes any legal liability or responsibility for the accuracy, completeness or usefulness of any information, apparatus, product or process disclosed, or represents that its use would not infringe privately owned rights. 


\section{DISCLAIMER}

This report was prepared as an account of work sponsored by an agency of the United States Government. Neither the United States Government nor any agency Thereof, nor any of their employees, makes any warranty, express or implied, or assumes any legal liability or responsibility for the accuracy, completeness, or usefulness of any information, apparatus, product, or process disclosed, or represents that its use would not infringe privately owned rights. Reference herein to any specific commercial product, process, or service by trade name, trademark, manufacturer, or otherwise does not necessarily constitute or imply its endorsement, recommendation, or favoring by the United States Government or any agency thereof. The views and opinions of authors expressed herein do not necessarily state or reflect those of the United States Government or any agency thereof. 


\section{DISCLAIMER}

Portions of this document may be illegible in electronic image products. Images are produced from the best available original document. 


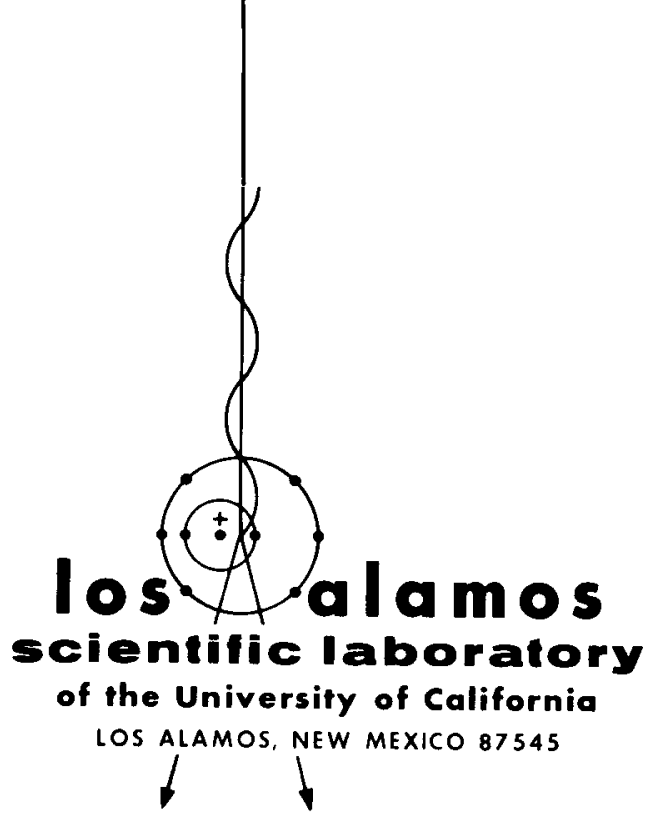

\section{Application of the Complex Equilibrium Code QUIL to Cesium-Impurity Equilibria in the Primary Coolant of High-Temperature Gas-Cooled Reactors}

by

R. C. Feber

J. L. Lunsford

W. A. Stark, Jr. 


\title{
APPLICATION OF THE COMPLEX EQUILIBRIUM CODE QUIL TO CESIUM-IMPURITY EQUILIBRIA IN THE PRIMARY COOLANT OF HIGH-TEMPERATURE GAS-COOLED REACTORS
}

by

R. C. Feber, J. L. Lunsford, and W. A. Stark, Jr.

\begin{abstract}
An equilibrium analysis has been made of the fission-product cesium in the primary coolant loop of the high-temperature gas-cooled reactor (HTGR). The species distributions that result at equilibrium have been calculated for various conditions of reactor operation. The cesium species considered were the monomer, dimer, oxides, hydroxides, and the hydride. The effect of cesium sorption isotherms on graphite also was included in the analysis.

During normal reactor operations, the abundant species of cesium were calculated to be elemental cesium, $\mathrm{Cs}$, and the monomeric hydroxide, $\mathrm{CsOH}$. Under most conditions of steam ingress, the abundant species was calculated to be $\mathrm{CsOH}$.

Cesium adsorbed onto graphite was stable under all steam-ingress conditions considered. Thermal transients above $1500 \mathrm{~K}$ were required for equilibrium transport of cesium from the core to the coolant.

The analysis was carried out using the complex equilibrium code QUIL, designed and written with special emphasis on features that make it applicable to the fission-product problem.
\end{abstract}

\section{INTRODUCTION}

Complex equilibrium codes are powerful tools with which to study the high-temperature gas-cooled reactor (H'TGR). Recent studies include an investigation into the chemical conditions that would prevail in the coolant of an HTGR in the event of water ingress into the primary coolant loop where graphite is present.'

The purpose of this report is to apply complex equilibrium calculations to the primary coolant loop of an HTGR, assuming that impurities from the graphite-water reaction and a fission product are present simultaneously in the helium gas. In particular, fission-product cesium is treated because cesium adsorption on nuclear graphite has been studied experimentally and because thermodynamic data exist for a number of gaseous species of cesium, including the monomer, dimer, oxides, hydroxides, and the hydride.

The computer program program QUIL, with which these calculations have been made, is still under development, but the goal is a program and data file which can be applied to a wide variety of fission products and their distribution between chemical species under various reactor conditions. 
The chemical environment of the HTGR is of concern both in normal and off-normal reactor operating conditions. To specify these environments precisely, only rate-dependent calculations should be used, because even in steady-state conditions chemical species in the primary loop usually will not be at thermodynamic equilibrium. However, for two reasons it is probably not wise to treat as a rate problem a system containing multiple fission-product species in an HTGR environment. Not all of the necessary rate parameters are known, and the rate calculation can be simplified by using equilibrium calculations to identify key species. Still, complex equilibrium calculations can provide insight into the nature of the reactor environment. Such calculations certainly indicate the final concentration of each species at equilibrium and, when properly used, indicate the bounds imposed by a given rate-dependent process. For example, complex equilibrium calculations that assume, in turn, the presence and the absence of free carbon can serve to bound the chemical distributions in the loop with respect to carbon oxidation if the rest of the chemical system is at equilibrium.

\section{METHOD}

From the voluminous literature on the calculation of complex chemical equilibria, van Zeggeren and Storey ${ }^{2}$ have made an excellent summary of many of the methods. The large number of calculational methods reflects the difficulty of devising computational algorithms that are consistent with limitations on program size and/or running time in many computers.

Complex equilibrium codes compute the distribution of species in chemical environments. Many numerical techniques can be used to carry out such calculations, but most approaches fall into one of two categories: the code represents either a free-energy minimization algorithm or a nonlinear system solver. In either case, the goal is to specify the state of the system at equilibrium. In this sense, the calculation represents an implementation of equilibrium thermodynamics.

QUIL is an example of a nonlinear system solver. The complex equilibrium problem is defined by stating a temperature, a pressure, those chemical elements whose total amounts are to be conserved (the gross stoichiometry), the species assumed to be present at equilibrium, the reactions by which to link these species, and the free energies or equilibrium constants of these reactions. From the stoichiometry we get a set of mass balance equations, and from reactions we get a set of equilibrium relations. The temperature and the pressure specify the equilibrium conditions. The necessary thermodynamic data can then be obtained from standard tables or by other means, and the set of mass balance and equilibrium equations can be solved by whatever method is selected.

In QUIL, we take $\mathrm{A}, \mathrm{B}, \ldots, \mathrm{L}, \mathrm{M}, \ldots$ as the species that are present and which are linked by a general reaction of the form

$\mathrm{aA}+\mathrm{bB}+\ldots=1 \mathrm{~L}+\mathrm{mM}+\ldots ; \Delta \mathrm{G}^{\mathrm{O}}$

where the values $a, b, \ldots, 1, m, \ldots$ are the species reaction coefficients and $\Delta \mathrm{G}^{\circ}$ is the accompanying free-energy change in the standard state. If we have $M_{K}$ moles of a species $K$ in a phase $J$ containing a total of $M$, moles of all species at a total pressure $P$, we may take the activity $A_{k}$ of any species present as

$A_{K}=\frac{M_{K}}{M_{J}} \delta_{J}$ 
where $\delta_{\text {, }}$ is a delta function

$\delta_{j}=\left\{\begin{array}{l}0, j \neq \text { gas }, \\ 1, j=\text { gas. }\end{array}\right.$

From the definition of the equilibrium constant, we have

$\frac{{ }_{{ }_{L} A_{M}^{m}}^{m}}{A_{A}^{a} A_{B}^{b} \cdots}=k^{0}$,

where the A's are the activities of the set of species present. The equilibrium constant $\mathrm{K}^{\circ}$ is related to the free-energy change $\Delta G^{\circ}$ by an expression of the form

$\Delta G^{0}=-\operatorname{RTLn}\left(K^{\circ}\right)$,

where $\mathrm{R}$ is the gas constant and $\mathrm{T}$ is the absolute temperature.

Typical values of the equilibrium constant as defined above may range from $10^{+50}$ to $10^{-150}$. If an equilibrium constant became small compared with machine round-off in a particular calculation, we anticipated difficulty in obtaining a solution from such a set of equations. Accordingly, we decided to work with a logarithmic form of Eq. (4) because the logarithm of even a small equilibrium constant would hardly be smaller than machine round-off. If one denotes the coefficient of the species $\mathrm{K}$ in equation $\mathrm{N}$ by $\mathrm{S}_{\mathrm{NK}}$, then the definition of the equilibrium constant can be written in logarithmic form as

$\sum_{\mathrm{K}} \mathrm{S}_{\mathrm{NK}} \operatorname{Ln}\left(\mathrm{A}_{\mathrm{K}}\right)=\operatorname{Ln}\left(\mathrm{K}_{\mathrm{N}}^{\mathrm{O}}\right)$,

where the coefficients on the left-hand side of Eq. (1) are taken as negative. Accordingly, we take the set

$(E R R)_{N}=\sum_{K} S_{N K} \operatorname{Ln}\left(A_{K}\right)-\operatorname{Ln}\left(K_{N}^{o}\right)$

as $\mathrm{N}$ error conditions which the system solver must drive toward zero.

QUIL, which employs both the Gauss-Newton and the Newton-Raphson methods, requires the Taylor's series expansion through the linear term of the various error components in the problem. The independent variables are taken as the moles of species present in the chemical environment. We therefore require the partial derivatives of these various error components with respect to $\mathrm{M}_{\mathrm{L}}$, the moles of species $\mathrm{L}$ that are found in $\mathrm{M}_{\mathrm{l}}$, the moles of phase I. The partial derivative of an equilibrium error component becomes

$\frac{\partial(E R R) N}{\partial M_{L}}=\frac{S_{N L}}{M_{L}}-\sum_{K} \frac{S_{N K}}{M_{I}}$,

where the summation extends over all species $\mathrm{K}$ common to phase I. Activities are frequently as small as $10^{-100}$. For species present in such small amounts, the leading term in Eq. (8) dominates because it is inversely proportional to $\mathrm{M}_{\mathrm{l}}$. Thus, these partials, which are the components of the normal matrix, tend to very large numbers and the value of the determinant tends to infinity. This problem can be resolved by the change of variable 
$Q_{K}=\operatorname{Ln}\left(M_{K}\right)$

Since

$\frac{\partial Q_{K}}{\partial M_{K}}=\frac{1}{M_{K}}$

and

$\frac{\partial(F R R)}{\partial Q_{K}}=\frac{\partial M_{K}}{\partial Q_{K}} \frac{\partial(E R R)_{N}}{\partial M_{K}}$.

we have

$\frac{\partial(E R R) N}{\partial Q_{K}}=M_{K} \frac{\partial(E R R) N}{\partial M_{K}}$

or

$\frac{\partial(E R R)_{N}}{\partial Q_{L}}=S_{N L}-\sum_{K} s_{N K} \frac{M_{L}}{M_{I}}$.

These partials are of the order of $S_{N L}$ because the ratios $\left(M_{L} / M_{1}\right)$ range from zero to one. The matrix components arising from the products of these partials are therefore of the order of unity.

If the various species are composed of $M$ elements, there are at most $M$ mass balances which can be written as conservation conditions. First denote the number of moles of an element $\mathrm{M}$ in one mole of a species $\mathrm{K}$ as the element reaction coefficient $\mathrm{E}_{\mathrm{MK}}$. If the number of moles of an element present in the system is $\mathrm{M}_{M}$, then the $\mathrm{M}$ mass balances may be written

$\sum_{K} E_{M K} M_{K}=M_{M}$

From these we can write the set

$(E R R)_{M}=\sum_{K} E_{M K} M_{K}-M_{M}$

as $\mathrm{M}$ error conditions which the system solver must also drive toward zero.

The partial derivative of a stoichiometric error component becomes

$\frac{\partial(E R R) M}{\partial Q_{L}}=M_{L} \frac{\partial(E R R) M}{\partial M_{L}}$

or

$\frac{\partial(\text { ERR })}{\partial Q_{L}}=M_{L} E_{M L}$. 
When species are present in small amounts, these partials, which are the components of the normal matrix, tend to very small numbers and the value of the determinant tends to zero. This problem can be resolved by dividing the stoichiometry relations of $\mathrm{Eq}$. (15) by $\mathrm{M}_{n}$. With this change, we have

$(E R R)_{M}=\sum_{K} E_{M K} \frac{{ }_{K} K}{M_{M}}-1$

and

$\frac{\partial(E R R) M}{\partial Q_{L}}=E_{M L} \frac{M_{L}}{M_{M}}$.

These partials are of the order of $E_{M L}$ because the ratios $\left(M_{1} / M_{M}\right)$ range from zero to one. The matrix components arising from the product of these partials are therefore of the order of unity.

In summary, we evaluate the Taylor's series expansion for $\mathrm{N}$ error conditions of the form

$(E R R)_{N}=\sum_{K} S_{N K} \operatorname{Ln}\left(A_{K}\right)-\operatorname{Ln}\left(K_{N}^{o}\right)$

and $\mathrm{M}$ error conditions of the form

$(E R R)_{M}=\sum_{K} E_{M K} \frac{M_{K}}{M_{M}}-1$

to solve for the $K$ values of $Q_{K}$, where

$Q_{K}=\operatorname{Ln}\left(M_{K}\right)$

and

$M+N=K$.

Written thus, the overall system minimizes the possibility of ill-conditioning, because all matrix components are of the order of unity.

Fission-product studies on the primary coolant loop of an HTGR must be made with initial fission-product activities as much as 15 to 20 orders of magnitude below those of other gaseous species. The activities of many of the species included in such a calculation will then fall by another 20 to 30 orders of magnitude in the final equilibrium distribution. Species that are present in "trivial" quantities may make up the total amount from a particular fission product. Finally, species that are insignificant over a limited range of a calculation may become important in some other part of the calculation. If one includes multiple phases in the calculation, approximate or stepwise solution techniques become difficult to apply. QUIL, operating as a single-pass, nonapproximate system solver has extracted solutions with well-behaved minima when concentrations differed by 160 orders of magnitude. 


\section{SYSTEM SOLVERS AND SEARCH TECHNIQUES}

It was desirable that QUIL should be able to handle a wide variety of problems and yet be efficient with regard to running time. Because the more powerful system solvers and search techniques usually require more time in execution, QUIL is written in levels so that the simplest method applicable is always the one in use. At each stage of the calculation, various tests are made for approach to convergence, ill-conditioning, singularity, etc., and appropriate changes are made in the solver/search strategy. In essence, QUIL changes techniques under program control to meet the conditions existing at any point during execution. This feature allows the code to optimize itself continually against the problem during execution and increases its applicability to a wider range of problems.

The complete specification of the search strategy is too extensive to be covered here, but the general features of the system solver and the direct-search philosophy are detailed below. QUIL employs both the Gauss-Newton method and the Newton-Raphson method. The first technique emphasizes speed, whereas the second is a more powerful system solver. During each iteration, one of the two methods is used exclusively. Therefore, at the start of each iteration, a decision is made as to which technique to employ.

The Taylor's series expansions of the $K$ error components have been evaluated in the previous section. With a change in notation, the form of the linearized expansion of an error component $\mathrm{E}_{\mathrm{n}}$ becomes

$E_{n}=E_{n o}+\sum_{k=1}^{K} \frac{\partial E_{n}}{\partial p_{k}} q_{k} ; n=1, \ldots, K$,

where $q_{k}$ is the incremental change in the parameter $p_{k}$. Let the matrix component $a_{n h}$ be written

$a_{n k}=\frac{\partial E_{n}}{\partial p_{k}}$.

with the vectors $e, p$, and $q$ defined as

$$
\begin{aligned}
& e=\left(E_{10}, E_{20}, \ldots, E_{K o}\right)^{T}, \\
& p=\left(p_{1}, p_{2}, \ldots, p_{K}\right)^{T},
\end{aligned}
$$

and

$q=\left(q_{1}, q_{2}, \ldots, q_{K}\right)^{T}$,

we have the Taylor's series expansion in matrix form as

$$
\mathrm{Aq}=-\mathrm{e},
$$

where $\mathrm{q}$ is the incremental change in $\mathrm{p}$ for $\mathrm{E}_{\mathrm{n}}=0.0$.

QUIL first attempts a solution by the Gauss-Newton method. Multiplying Eq. (29) by $A^{T}$, we have

$\left(A^{\mathrm{T}} A\right) q=B q=-A^{\mathrm{T}} \mathrm{e}$, 
where B is the normal matrix for the system. Multiplying Eq. (30) by the inverse of the normal matrix, we have

$$
q=-B^{-1} A^{T} e
$$

where $q$ is now the vector correction to $p$.

Equation (31) is solved in subroutine SYST which calls a standard library routine that employs pivoting and double precision accumulation of inner products. This standard library routine has the advantage of being fast. However, as Eq. (31) indicates, the GaussNewton method requires considerable computational manipulation of the original Taylor's series expansions. When the original system of equations is ill-conditioned, the formation of the inverse $\left(\mathrm{A}^{\mathrm{T}} \mathrm{A}\right)^{-1}$ increases ill-conditioning, and the Gauss-Newton method will give poor results. To test for this eventuality, the routine is entered twice. On the first pass, the determinant of the system is computed and Eq. (30) is normalized. On the second pass, the value of the determinant should be 1.0. If the determinant is 1.0 to preset limits, the GaussNewton method is used for all further calculations required during that iteration.

If the second pass through the standard library routine reveals that the determinant is no longer 1.0 to desired accuracy, a flag is set indicating that the input system is illconditioned, and QUIL resorts to the Newton-Raphson method to solve Eq. (29). Since the Newton-Raphson method works with the original Taylor's series expansion [Eq. (29)], deterioration of conditioning is avoided. This is an important feature of the technique. To solve the original system, a second slower but more powerful library routine is then called to extract the solution. This more generalized system solver employs the method of minimum least squares as proposed by Osborne. ${ }^{3}$ This generalized routine can extract solutions in the least-squares sense from systems of equations that are under-determined, square, or overdetermined. For the remainder of the iteration, the Newton-Raphson method is used for all calculations.

Direct-search capabilities in QUIL are derived from two parameters which may be varied to produce local minima in the computed value of the sum of the squares of the errors. The first is the Levenberg-Marquardt parameter. ${ }^{4,5}$ To illustrate how this parameter is used, we rewrite a modified version of $\mathrm{Eq}$. (29) in partitioned form as

$\left[\begin{array}{c}\mathrm{A} \\ 1 \\ \mathrm{r}^{2} \mathrm{I}\end{array}\right]\left\{\begin{array}{l}\mathrm{q} \\ 0\end{array}\right\}=\left\{\begin{array}{c}-\mathrm{e} \\ 0\end{array}\right\}$,

where $o$ is a null vector of dimension $\mathrm{K}, \mathrm{I}$ is the unit matrix of dimension $\mathrm{KxK}$, and $\mathrm{r}$ is the Levenberg-Marquardt parameter. In light of Eq. (32), Eq. (30) becomes

$\left(A^{T} A+r I\right) q=B^{\prime} q=-A^{T} e$,

which redefines the normal matrix for the system.

QUIL is written to minimize a function $\phi$, which is the sum of the squares of the error components $E_{k}$, as defined in Sec. II.

Thus

$\phi=\sum_{k} E_{k}^{2}$.

The negative gradient $\mathbf{g}$ is the slope of $\phi$ in parameter space. 
Thus

$z_{j}=-\frac{\partial \dot{\xi}}{\partial p_{j}}=-2 \sum_{k=1}^{k} E_{k} \frac{\partial E_{k}}{\partial p_{j}} ; j=1, \ldots, k$,

or, in vector form

$\varepsilon=-2 \Lambda^{\mathrm{T}} \mathrm{e}$.

Combining Eqs. (33) and (36), we have

$\left(\hat{A}^{\mathrm{T}} \mathrm{A}+\mathrm{x} ; \mathrm{q}\right)=\frac{\mathrm{g}}{2}$

From Eq. (37), we can see the effect of $r$ upon the solution vector $q$. When $r$ tends to zero, $q$ tends to the unperturbed Gauss-Newton solution. When $r$ tends to infinity, $q$ tends to $g /(2 r)$. The advantage of the $r$ parameter is that it can cause a continuous rotation of the solution vector from the negative gradient direction to the Gauss-Newton direction. An analogous argument holds for the Newton-Raphson method.

The disadvantage of the Levenberg-Marquardt parameter is the length change it produces in the solution vector. To compensate for this second effect, we introduce a second parameter, $t$, which is simply a factor by which to scale the solution vector. Thus, as a result of the $i^{\text {th }}$ iteration, we replace the current value of the parameter vector $p_{1}$ with an updated version

$p_{i+1}=p_{i}+t q(r)$

as a starting point for the next iteration. Both $\mathrm{t}$ and $\mathrm{r}$ are subjected to direct-search techniques.

Figure 1 is a schematic of a hypothetical search that might take place during a typical iteration. When the $\mathrm{r}$ parameter is employed, considerable computing time is expended because the system solver must be entered for each calculation. To minimize the use of the $r$ method, the calculation is initiated as a one-dimensional search in the $t$ direction with $r=0$. The search proceeds in two phases. In the first phase, a set of three equidistant points is moved along the $t$ axis in what is called here a tripod search. The location and spacing of these three points are varied until a minimum, $t_{1}$, is located with a satisfactory standard deviation of the sum of the squares of the errors at the three points in question. The second phase of the search, called here a parabolic search, is conducted by fitting a parabola to these three points, computing a new predicted minimum, and selecting a new set of points by which to continue the algorithm. In this selection process, the lowest point and its nearest neighbor on each side are always selected as the new set of values with which to continue the search. In this manner, the iterative process is guaranteed to be stable. When this algorithm fails to find a new minimum smaller than the old minimum, the parabolic search is abandoned. The first phase of the search results in a set of three values of $t$ clustered about the final minimum, from which we calculate a radius which is half the span of these three values. The second phase of the search results in an improved estimate of that minimum.

With these values of the minimum and a radius, the two-dimensional search, called here a semicircular search, is entered. The second search variable is the angle of the radius vector from the minimum $t_{1}$. A search then proceeds in two phases, as described above. First, a tripod search locates a minimum with an acceptable standard deviation. A parabolic search 


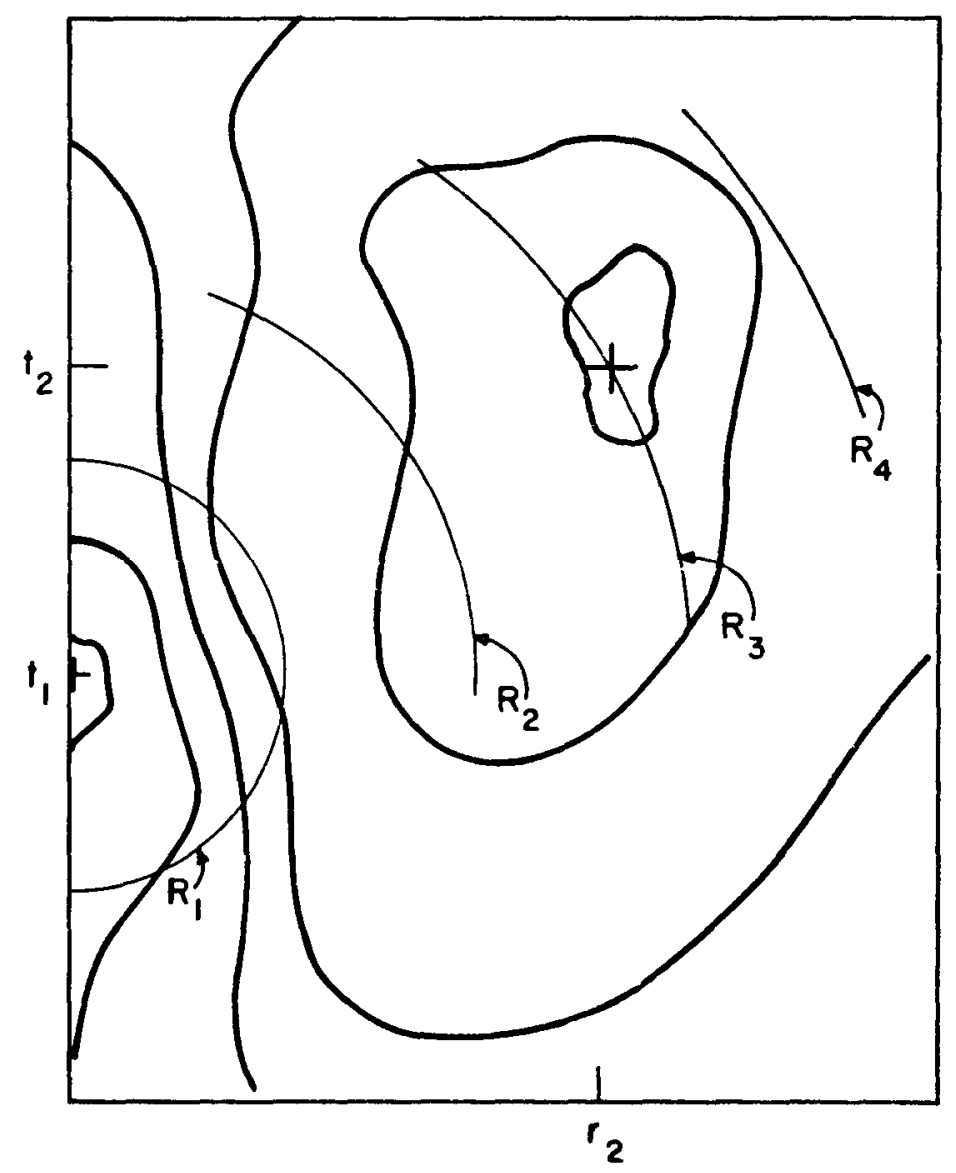

Fig. 1.

Two-dimensional search in the $t-r$ plane leading to a solution at $\left(t_{2}, r_{2}\right)$ with a radius $R_{3}$. 
improves the estimate of that minimum. The radius is then doubled, and the same procedure is carried out at the new radius. When the search conducted at the larger radius reveals a new minimum that is larger than the old minimum, the semicircular search is abandoned. Values of $t_{2}$ and $r_{2}$ at the minimum are stored as adjuncts to the final solution.

When large gains are being made by the one-dimensional $t$ search, the semicircular search rarely reveals lower minima. Therefore, simple problems tend to operate without entering into the t-r search for more than one pass, and computing time is conserved. When only slight gains are effected by the one-dimensional search, the semicircular search almost always reveals a minimum lower than that found at $t_{1}$, and the search travels out into the $t-r$ plane. Thus the search strategy tends to adjust itself automatically, and the use of computing time is optimized.

When the correction vector becomes smaller than a preset limit, the direct search is bypassed, and the direct jump is taken with $r=0.0$ and $t=1.0$. Convergence is assumed when successive iterations do not reduce the sum of the squares of the errors after a direct jump.

Initial stoichiometries may differ by many orders of magnitude, so to minimize execution time it is important to have a good starting approximation to the solution vector. An initial estimate is achieved in the following manner. First, one selects the element $\mathrm{E}$ that is present in the smallest quantity $\mathrm{M}_{\mathrm{L}}$. If there are $\mathrm{L}$ species present containing that element, the $\mathrm{L}$ species are all assigned a starting value of $\mathrm{M}_{\mathrm{t}} / \mathrm{L}$ moles. The program cycles in this fashion through the elements present from the least abundant to the most abundant. Thus, a starting solution within several orders of magnitude of the final answer is obtained for all but a few species. It is a trivial computational step, but it saves a great deal of computing time.

When the code goes into execution, if only one phase is present, the code enters a preprocessor mode. In this mode the initial approximate solution is used to calculate an improved distribution by assuming that the equilibrium constants are all one and the stoichiometry will dictate the distribution. When QUIL converges in the preprocessor mode, the code resets the equilibrium constants to their proper values. This last approximation to the solution then becomes the starting point for calculating the final distribution.

\section{INPUT/OUTPUT}

The primary purpose of QUIL is to calculate and present equilibrium compositions in both tabular and graphical form. The code was also intended to be fast and flexible, so that questions involving complex equilibria could be simply posed and quickly answered. The code could thus be an analytical tool in the study of the chemistry of the primary coolant loop of the HTGR.

To this end, several convenience features have been incorporated into QUIL. QUIL is an interactive code. It is put into execution without input data. Once in execution, the code asks the programmer for certain information through the medium of a keyboard terminal. This means that the input is format-free and that input branching takes place under program control.

As another convenience feature, QUIL is terminated in a front-end preprocessor that accepts as input a chemical statement of the problem, i.e., the equilibrium equations in conventional form. Table I shows input that QUIL would interpret as a problem statement. The code recognizes the conventional meaning of the mnemonic relations. In addition, QUIL will accept relations that are tagged with the standard free energy of reaction, $G$, or the logarithm of the equilibrium constant, $\mathrm{K}$. The numerical expression used to tag the mnemonic expression must be of the form given by theory. ${ }^{6}$ This form is a power series in the temperature $\mathrm{T}$, to which is added a term in $\operatorname{Ln}(\mathrm{T})$. In particular, a term in $\mathrm{T}^{*} \mathrm{Ln}(\mathrm{T})$ may be added to the expression for the free energy of reaction and a term in $\operatorname{Ln}(\mathrm{T})$ may be added to 


\title{
TABLE I
}

\section{EXAMPLE OF TYPICAL INPUT TO QUIL}

\author{
1. $\mathrm{He}(\mathrm{g})$ \\ 2. $\mathrm{C}(\mathrm{s})$ \\ 3. $\mathrm{CsH}(\mathrm{g})=\mathrm{Cs}(\mathrm{g})+0.5 \mathrm{H}_{2}(\mathrm{~g})$ \\ 4. $\mathrm{CsOH}(g)=\mathrm{Cs}(\mathrm{g})+0.5 \mathrm{O}_{2}(\mathrm{~g})+0.5 \mathrm{H}_{2}(\mathrm{~g})$ \\ 5. $\mathrm{H}_{2} \mathrm{O}(\mathrm{g})=\mathrm{H}_{2}(\mathrm{~g})+0.5 \mathrm{O}_{2}(\mathrm{~g})$ \\ 6. $\mathrm{CO}_{2}(\mathrm{~g})=\mathrm{C}(\mathrm{s})+\mathrm{O}_{2}(\mathrm{~g})$ \\ 7. $\mathrm{CO}(\mathrm{g})=\mathrm{C}(\mathrm{s})+0.5 \mathrm{O}_{2}(\mathrm{~g})$ \\ 8. $\mathrm{CH}_{4}(\mathrm{~g})=\mathrm{C}(\mathrm{s})+2 \mathrm{H}_{2}(\mathrm{~g})$ \\ 9. $\mathrm{CsO}(\mathrm{g})=\mathrm{Cs}(\mathrm{g})+0.5 \mathrm{O}_{2}(\mathrm{~g})$ \\ 10. $\mathrm{Cs}_{2}(\mathrm{~g})=2 \mathrm{Cs}(\mathrm{g})$ \\ 11. $\mathrm{Cs}_{2}(\mathrm{OH})_{2}(\mathrm{~g})=2 \mathrm{Cs}(\mathrm{g})+\mathrm{O}_{2}(\mathrm{~g})+\mathrm{H}_{2}(\mathrm{~g})$ \\ 12. $\mathrm{Cs}_{2} \mathrm{O}(\mathrm{g})=2 \mathrm{Cs}(\mathrm{g})+0.5 \mathrm{O}_{2}(\mathrm{~g})$
}

the expression for the logarithm of the equilibrium constant. For reactions where no equilibrium data are input, QUIL goes to the library.

The system solver in QUIL needs a numerical array, and a mnemonic array is indicated. One implies the other, and as a further convenience to the programmer, QUIL deduces the numerical array implied by the mnemonic array. To do this, QUIL first breaks down the equations as written to determine the elements present, the species present, and the element and species coefficient matrices. It then writes the equilibrium relations as $\mathrm{N}$ Taylor's series expansions-of-error conditions that must be driven toward zero in order to solve the problem.

At this point, the problem is still not soluble; there are more unknowns than conditions because of the absence of the stoichiometry relations. However, these relations are not unique because they are implied by the set of equilibrium relations. Again, as a convenience to the programmer, QUIL writes the mass balance conditions as M Taylor's series expansionsof-error conditions that must be driven toward zero to solve the problem. These $M+N$ error conditions are written in terms of the moles of the $\mathrm{K}$ species present in the starting stoichiometry, where $\mathrm{K}=\mathrm{M}+\mathrm{N}$.

Other features have been incorporated into QUIL to increase its convenience and utility. Of interest are instances of mixed equilibria wherein certain reactions in a system are assumed to be in equilibrium while others are not. For example, one might wish to partition equilibrium in a given system by assuming gas-gas equilibrium in the absence of gas-solid equilibrium. The code will allow such conditions of partitioned equilibria to be imposed, and will calculate the potential to occur for reactions that are assumed to be out of equilibrium. These "reaction potentials" are then plotted over the range of the calculation. 
QUIL will also allow the reactions in the library to be loaded as sums and differences. Thus reaction potentials can be computed for all possible reactions in the system. As an example, consider the two reactions

$\left.\mathrm{CO}_{\mathrm{A}}\langle\mathrm{B}\rangle=\mathrm{C}: s\right\rangle+\mathrm{O}_{2}\langle\mathrm{~g}\rangle$

and

$\operatorname{cosg}\rangle=\cos \rangle+0.5 \hat{0}_{2}\langle g\rangle$.

They could be solved under equilibrium assumptions to give the equilibrium distribution of species present-in this case, $\mathrm{CO}_{2}(\mathrm{~g}), \mathrm{CO}(\mathrm{g}), \mathrm{O}_{2}(\mathrm{~g})$, and $\mathrm{C}(\mathrm{s})$. The presence of solid carbon significantly affects the resultant distribution, and is equivalent to assuming that gas-solid equilibrium prevails. In the event that this assumption seems unwarranted, it is possible to solve for the following distribution instead. If one takes the difference of the two reactions presented above, one obtains

$\mathrm{CO}_{2}\langle\beta\rangle=0.5 \mathrm{O}_{2}\langle\xi\rangle+\mathrm{CO}\langle\mathrm{g}\rangle$

as a single reaction. The resultant distribution of species, when solved as above, is exactly that which would prevail if the system contained no free carbon. In effect, the system has been solved with the assumption that gas-gas equilibrium prevails, and that gas-solid does not.

Having excluded $\mathrm{C}(\mathrm{s})$ from the calculation, it is now of interest to know if the environment as calculated is predisposed to precipitate carbon or to react with it. Consider the definition of the equilibrium constant for the first reaction written above in Eq. (39)

$\mathrm{K}=\frac{\mathrm{P}_{2}}{\mathrm{P}_{2}}$.

Since the reaction was not included in the system as solved in the second instance [Eq. (41)], the equality as written in Eq. (42) is not satisfied. If one defines

$x^{\prime}=\frac{{ }_{\mathrm{o}_{2}}}{{ }_{\mathrm{CO}_{2}}}$,

where $\mathrm{K}^{\prime}$ is computed from the existing distribution solved in the absence of $\mathrm{C}(\mathrm{s})$, then the ratio

$R=\frac{K}{K^{\prime}}$

may be taken as a reaction constant. It is a measure of the extent to which the $\mathrm{CO}_{2}$ reaction [Eq. (39)] is out of balance in the reduced system of Eq. (41) and is thus a measure of the tendency or "potential" of the system to precipitate carbon from the gaseous environment assumed to be in equilibrium. The logarithm of the ratio of these two constants is then defined as a reaction potential. A positive reaction potential indicates a tendency for the reaction in question to run to the right as written.

Thermodynamic data are reduced to a standard format in a support code called FENG. Here, standard free energies of reaction are fitted to a power series in temperature to which a 
term has been added in $\mathrm{T}^{*} \operatorname{Ln}(\mathrm{T})$, which is given by theory. ${ }^{6}$ The fitting procedure requires that all parameters so fitted be statistically significant, where the test of significance is taken as the requirement that the parameter as fitted exceed by a factor of 2 the estimate of the standard deviation associated with the parameter in the fit. In the event that some parameters are insignificant after the fitting process, the parameter that is numerically the least significant is nulled, and the fitting process is entered again with one less free parameter. When all free parameters are statistically significant, the parameters and the associated data are loaded into the reference library. This library, which is on permanent file, is called by QUIL for all of the free-energy data needed for the calculation.

\section{SURFACE PHASES}

Cesium forms surface phases on carbon and graphite. Experimental results indicate that the sorption isotherms of cesium on reactor-grade graphite in the sub-monomolecular range can be expressed by the equation

$$
\log (\mathrm{C})=\frac{1}{\mathrm{~S}} \log (\mathrm{P})+k
$$

where $\mathrm{C}$ is the cesium surface coverage, $\mathrm{P}$ is the equilibrium partial pressure of the cesium over the isotherm, $\mathrm{S}$ is a function of the graphite and the temperature, and $\mathrm{k}$ is a function of temperature. Equation (45) is a form of the standard Freundlich equation for isotherms.

In principle, the introduction of surface phases into QUIL should proceed in a straightforward manner. In practice, however, some difficulties may be encountered. The data necessary to specify a set of adsorption isotherms over the desired temperature-pressure regime are not always available. More troublesome is the fact that equilibrium relations may be expressed in widely divergent mathematical forms. Also, variances exist between authors and techniques. In general, some compromises are required before one can proceed with the problem.

Existing data for cesium adsorption have been obtained with a wide range of techniques and under a variety of conditions ${ }^{8-23}$ Some of the work is not applicable to the purpose at hand, and that which is applicable has been done at near or below monolayer coverage. Data taken at a constant temperature to elucidate the sorption processes are insufficient for a temperature-dependent, parametric model. ${ }^{8}$ Furthermore, there is a lack of unanimity in the literature with regard to the shape of the cesium isotherm, and results are dependent on the type of graphite or carbon as well as the manufacturing process. At sub-monolayer coverage, the pseudoisopiestic method produces isotherms with straight-line Freundlich plots, ${ }^{9}$ whereas at comparable cesium pressures the Knudsen-cell mass spectrometric technique produces isotherms that have curved Freundlich plots. ${ }^{10}$ These same investigators report that experimental conditions are not responsible for the variation between techniques. ${ }^{11}$ (No data were available for Knudsen-cell tracer techniques.) Also, measurements on irradiated and nonirradiated graphite indicating differences in sorbtivity factors of 7 to 10 for fast fluences in the range of $3 \times 10^{21} \mathrm{n} / \mathrm{cm}^{2}$ have been reported. ${ }^{9.13}$ Finally, workers state that the ability to make "extrapolation is doubtful," and imply that extrapolation of existing data into areas of mixed isotherms is "uncertain at best."12 Some data indicate Freundlich behavior at the lowest experimental cesium pressures ${ }^{8,10.16}$ whereas other references indicate a transition from Freundlich to Langmuir behavior at low pressure. ${ }^{9.12 .14 .15}$ One worker reported an isotherm that plotted as a straight line in several regions of the data. ${ }^{18}$ 


\section{PARAMETRIC MODEL FOR CESIUM ADSORPTION}

QUIL is a nonlinear least-squares system solver. To treat surface phases, QUIL needs a computational means of calculating the gas pressure over the surface phase and the partial derivatives of the pressure with respect to the concentration variables in the problem. To this end, a parametric model is first fitted to the data. The difficulties mentioned in the previous section make this the most troublesome step in the process. However, once the data are properly fitted, QUIL gives distributions in accord with that fitting. If one examines a typical equilibrium distribution of species, one sees concentration differences of 50 to 75 orders of magnitude. Small variations in the goodness of fit in the parametric model will have a small effect on the final equilibrium distribution.

The parametric model treats the problem in terms of a surface phase with related activity coefficients. The choice of the model was influenced by ease of fitting, generality, and economy of parameters. No physical process is intended by the model. On the contrary, it is a formalism for fitting existing data and extrapolating to higher and lower coverages in a manner consistent with observed breaks in sorption isotherms and a simplified picture of gas-surface equilibria. It is hoped that this general approach will allow for treatment of a wide variety of problems with a minimum of specialization.

It is not easy to decide which experimental data to model. The library can handle as many isotherms as are desired, and QUIL can treat many cases simultaneously, so any number of combinations of experimental data is computationally possible. For a first case, we selected data representing the widest possible range of experimental pressure and temperature, thereby minimizing the extrapolation required for any given calculation. Two sets of data are noteworthy for their completeness: the work by Milstead, Riedinger, and Zumwalt ${ }^{16}$ on reactor-grade HLM-85 graphite taken over 5 orders of magnitude of cesium pressure and the work by Milstead ${ }^{14.15}$ on reactor-grade TS- 688 graphite taken over 8 orders of magnitude of pressure. Both sets of data were taken by the pseudoisopiestic method and gave straight-line Freundlich plots. The second set of data by Milstead was selected because it represented a wider range of pressures and projected into the Langmuir region at low pressures.

For purposes of the model it was necessary to provide for extrapolation to both cesium pressures and temperatures beyond the experimental range.

The temperature dependence of the Freudlich isotherm is generally accepted to be of the form of the Clausius-Clapeyron equation

$s=a+\frac{b}{I}$,

where $\mathrm{S}$ is the slope of the cesium vapor pressure in the Freundlich plot for data at the same fractional coverage, and the constant $b$ is interpreted as being proportional to the heat of adsorption at the fractional coverage.

A more detailed study of the Milstead data indicated that a better fit to the experimental data in the Freundlich region would result if a form linear with respect to temperature were selected. We therefore take

$\mathbf{S}=\mathbf{a}+b \mathrm{~T}$

as the parametric form for the slope in the Freundlich region. In particular, interpolation errors would be reduced for the calculations carried out in the range of the experiments. Accordingly, slopes were fitted to the form linear in temperature. The decision to use the linear form necessarily raises questions about using the model at temperatures far removed from the experimental region, since the linear and inverse forms will extrapolate to significantly different distributions. However, this effect is one of many errors invited by extrapolation 
and can be remedied only with experimental data that are valid over the range of computational interest.

We now proceed to a rationale of the pressure dependence of the model. Figure 2 indicates an idealized gas-surface equilibrium for a species adsorbed on a surface from a gas phase when no anomalous attractive forces exist at the surface. At high coverages the surface might be expected to act like a liquid surface above which the gas pressure is constant. Below some critical coverage $\mathrm{C}$, the logarithm of the gas pressure is proportional to the logarithm of the coverage. If, in addition, we take the proportionality constant as equal to unity, then we can define the activity coefficient of the adsorbed cesium as unity. For convenience we take the point of critical coverage to correspond to a monolayer.

Figure 3 indicates a possible equilibrium at constant temperature in the event that anomalous attractive forces exist between the adsorbate and the adsorbent. For convenience in discussion, the effect of this surface upon the adsorbate is divided into two regions. The first region ( $g-b$ ) is due to the creation of a monolayer from a liquid surface. The second (b-e) is due to the creation of a clean surface from a monolayer. Beginning at high concentrations, the idealized isotherm will behave like a liquid surface (g-f). As adsorbate is removed from the system, the liquid layer will become thinner at constant pressure. When this layer is thin enough, long-range forces associated with the adsorbent surface will no longer be shielded by the adsorbed layer. The point at which the adsorbent surface first begins to affect the equilibrium defines $\mathrm{C}_{3}$. If more adsorbate is removed from such a system, the surface concentration will fall ( $f-b)$ until it reaches monolayer coverage, which defines $C_{2}$. At this point, the "activity coefficient" of the adsorbate has decreased to $P_{b} / P_{a}$. Since $\log (P) \propto S^{*} \log (C)$, sorption characteristics are those of a Freundlich regime. If still more adsorbate is removed from the system, the surface concentration falls still further until it intersects the modified equilibrium curve at point $d$, which defines the concentration $C_{1}$. The modified curve is taken to be an extrapolation from the point $f$ of a line having unit slope. Between points $b$ and $d$ an additional decrease of the activity coefficient of the adsorbate occurs, and at point $\mathrm{d}$ it is equal to $\mathrm{P}_{\mathrm{c}} / \mathrm{P}_{\mathrm{a}}$. Below this concentration, $\log (\mathrm{P}) \propto 1.0^{*} \log (\mathrm{C})$, which is the definition of a Henry's law regime. Further removal of adsorbate from the system will not further change the activity coefficient of the surface.

The resultant curve e-d-b-f-g is the model to which the cesium data were fitted. The principal parameter to be fitted is $\mathrm{C}_{2}$, the concentration at monolayer coverage. The difference $\left(\mathrm{C}_{3}-\mathrm{C}_{2}\right)$ is the offset from monolayer coverage to the point at which the isotherm is pressureindependent. This latter point is assumed to occur at a pressure that is just the equilibrium pressure of the gaseous species over the liquid at temperature. The slopes of the straight-line segments $d-b$ and $b-f$ are computed as independent parameters in the model. Since the data are fitted in log-log coordinates, the entire plot can be relocated and redimensioned simply by specifying a new value of $\mathrm{C}_{2}$ in whatever units are applicable.

To express the temperature dependence of the model, we used truncated power series in temperature because it is a general approach and because it conforms to the literature on isotherms. However, problems may arise from extrapolation of parameters in expressions that must be non-negative. To insure the integrity of the model under all conditions, a general masking expression was chosen that guarantees non-negative values.

Consider a general function of temperature $H(T)$, which is negative over some part of its range. Let the function be embedded in an expression of the form

$P(T)=G * \log \left(1+10^{H(T) * F}\right)$, 


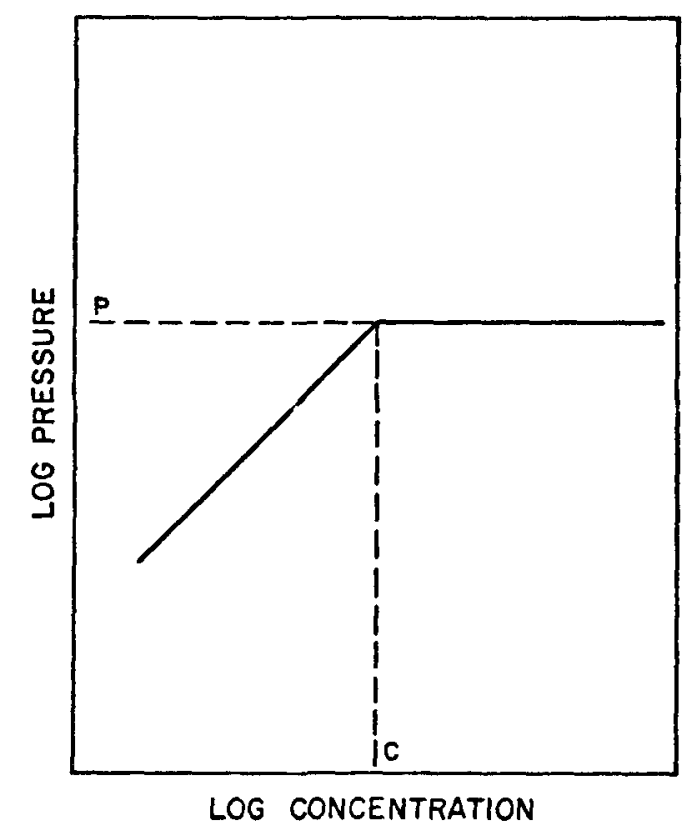

Fig. 2.

Idealized surface phase with an activity coefficient of unity independent of concentration.

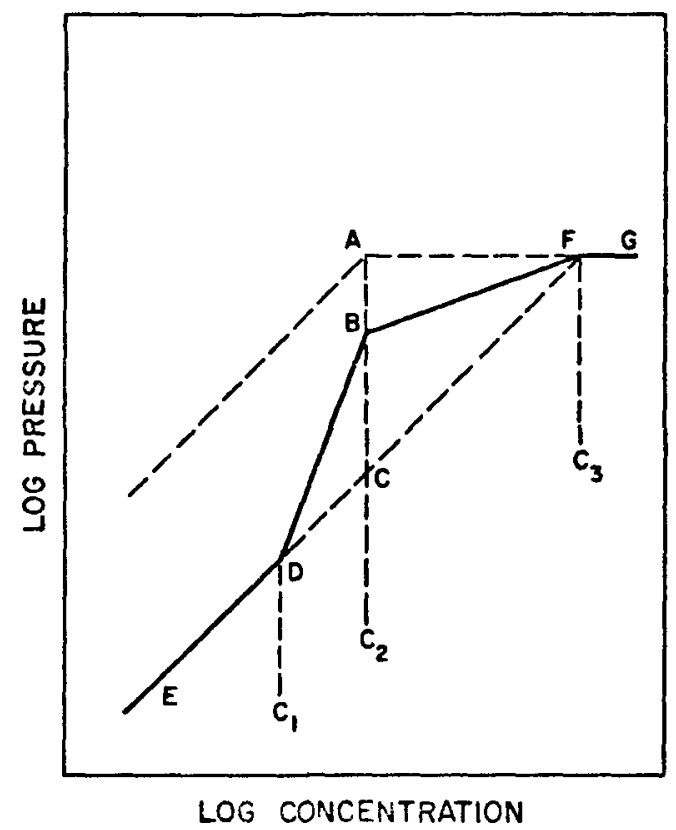

Fig. 3.

Idealized surface phase with an activity coefficient that is a function of concentration. 
where

$$
F=\frac{1}{G} \text {. }
$$

Then for all values for which the product $\mathrm{H}(\mathrm{T}) * \mathrm{~F}$ is large and positive, we have

$P(T)=H(T)$.

When the product $\mathrm{H}(\mathrm{T})^{*} \mathrm{~F}$ is large and negative, we have

$P(T)=0$

In the transition region, $\mathrm{P}(\mathrm{T})$ is dependent upon the magnitude of $\mathrm{F}$. Consequently, it was taken as a free parameter because it affects the fit. Varying forms of the above masking expression were used throughout the model.

The adsorption model is taken as a product of four functions

$P=P_{0} z_{0} z_{1}^{S}{ }_{1} z_{2}{ }^{S}$

where $P_{0}$ is a function of temperature alone, and the three functions $Z_{1}$ are functions of temperature and concentration. The function $\mathrm{P}_{0}$ is the equilibrium pressure of the species in question over whatever condensed phase is chosen as the reference phase. In the case of cesium, it is the liquid. The function is therefore that which is stored by FENG in the energy library, and the fitting process and the data format are those described in Sec. IV. Each of the three functions $Z_{1}$ controls the model in one of the three regions of Fig. 3.

Let the concentration of the adsorbate be $C$. Then the various values of $Z$ are given by

$$
z_{\bar{u}}=\frac{u_{1}}{\left(1+u_{1}{ }^{F}\right)^{G_{1}}},
$$

where

$$
u_{1}=\frac{c}{c_{1}}
$$

and

$$
G_{1}=\frac{1}{F_{1}}
$$

with $\mathrm{F}_{1}$ a free parameter. Also

$$
z_{1}=\frac{C_{1}\left(1+u_{1}\right)^{G_{1}}}{C_{2}\left(1+u_{2}\right)^{G_{2}}},
$$


where

$u_{2}=\frac{c}{c_{2}}$

and

$G_{2}=\frac{1}{F_{2}}$,

with $F_{2}$ a free parameter. Similarly

$z_{2}=\frac{c_{2}\left(1+u_{2}\right)^{G_{2}}}{c_{3}\left(1+u_{3}\right)}$,

where

$u_{3}=\frac{\mathrm{c}}{\mathrm{c}_{3}}$.

The breakpoints $C_{1}$ and $C_{3}$ are given by

$C_{3}=C_{2} *\left(2+10^{E_{H}}\right)^{G_{H}}$

and

$c_{1}=c_{2} *\left(\frac{c_{3}}{c_{2}}\right)\left(\frac{s_{2}-1}{s_{1}-1}\right)$,

where

$E_{H}=E_{H}^{*}\left(h_{0}+h_{1} * T\right)$

and

$c_{H}=\frac{1}{\vec{F}_{H}}$,

with $F_{11}, h_{0}$, and $h_{1}$ as free parameters. For the slope $S_{1}$, we have

$s_{1}=1+G_{A} * \log \left(1+1.0^{E_{N}}\right)$,

where

$E_{A}=F_{A}^{*}\left(a_{0}+a_{1}^{*} T-1\right)$ 
and

$G_{A}=\frac{1}{F_{A}}$,

with $F_{1}, a_{0}$, and $a_{1}$ as free parameters. For the slope $S_{2}$, we have

$s_{2}=0.5 *\left[1+\tanh \left(p_{0}+p_{1} * T\right)\right]$

with $\mathrm{p}_{\mathrm{s}}$ and $\mathrm{p}_{1}$ as free parameters.

As noted, the three constants $\mathrm{C}_{1}, \mathrm{C}_{2}$, and $\mathrm{C}_{3}$ are the three breakpoints in the model. $\mathrm{C}_{2}$ is a free parameter which centers the isotherm at monolayer coverage. $C_{3}$ is calculated from $\mathrm{C}_{2}$ by Eq. (61) and has a temperature dependence of the form $(\mathrm{a}+\mathrm{b} \mathrm{T})$. It is a measure of the total activity-coefficient decrease due to the isotherm. $\mathrm{C}_{1}$ is not independent, but is calculated from $S_{1}, S_{2}, C_{2}$, and $C_{3}$. The temperature dependence of slopes $S_{1}$ and $S_{2}$ is calculated from functions of the form $(a+b T)$. Thus there are seven parameters that control the temperature-dependent asymptotic shape of the isotherm. The remaining four parameters are necessary in fairing the asymptotes into one another.

A processor called ISOT decomposes the isotherm into the parametric model indicated above, and loads the parameters and the pressure reference into the reference library in a way similar to that used by FENG to reduce and load thermodynamic data for conventional reactions into the library. The results of the fitting for the TS-688 data are shown in Table II and plotted in Fig. 4.

TABLE II

PARAMETERS FOR CESIUM SORPTION ISOTHERM

\begin{tabular}{|c|c|c|}
\hline$\underline{\mathbf{P}}$ & Parameter & $\begin{array}{l}\text { Standard } \\
\text { Deviation }\end{array}$ \\
\hline $\mathrm{C}_{0}$ & 1.8000000000 & 0 \\
\hline$h_{0}$ & 25.1686559759 & 7.7432868554 \\
\hline$h_{1}$ & -0.0131704109 & 0.0050005943 \\
\hline $\mathrm{F}_{\mathrm{H}}$ & 1.0000000000 & 0 \\
\hline $\mathrm{p}_{\mathrm{o}}$ & -3.2754905236 & 2.0197120994 \\
\hline $\mathrm{p}_{1}$ & 0.0023454357 & 0.0015967467 \\
\hline$a_{0}$ & 28.5716943461 & 17.9549629174 \\
\hline$a_{1}$ & -0.0019359050 & 0.0161626940 \\
\hline $\mathrm{F}_{\mathrm{A}}$ & 0.1979529951 & 0.3767330595 \\
\hline $\mathrm{F}_{1}$ & 6.2613197058 & 30.6623162850 \\
\hline $\mathrm{F}_{2}$ & 3.0000000000 & 0 \\
\hline
\end{tabular}

\section{APPLICATION OF QUIL TO AN HTGR}

The procedure described in this report follows the changes in the distribution of species in the gaseous phase as a given initial stoichiometry is exposed to the following environments: first, the coolant loop channels; second, the pores of the graphite; and third, the presence of surface phases in the graphite. For these calculations, equilibrium conditions are selected that seem to match most closely the appropriate region of the reactor under study. In the 
coolant channels, gas-gas equilibrium is assumed to prevail, but gas-solid equilibrium is assumed to be inhibited. Within the pores of the graphite, the same calculations are conducted, but free carbon is assumed to be present. To account for the effect of surface phases, isotherms of cesium are included in the calculation.

\section{INITIAL STOICHIOMETRIES}

Calculations were carried out with experimental compositions reported for actual reactors, as well as with stoichiometries selected for computational purposes as illustrative of various levels of hypothetical water ingress. The experimental stoichiometries treated were those for the Ft. St. Vrain, Dragon, Peach Bottom, and AVR reactors. For calculations with experimental compositions, pressures were taken as reactor operating pressures. Stoichiometries for the experimental environments are listed in Table III. For calculations with the hypothetical environments, initial compositions were taken as the gaseous distribution of species that would prevail at equilibrium in a carbon/helium environment with 10 , 500 , or $10000 \mathrm{ppm}$ of water at a preselected temperature, usually $900 \mathrm{~K}$. For these hypothetical environments, the pressure was taken as $5050 \mathrm{kPa}(50 \mathrm{~atm})$. The resulting initial stoichiometries are listed in Table IV. They might be thought of as environments that would prevail at some time following a water ingress.

\section{THE GAS IN THE COOLANT CHANNEL}

For each stoichiometry studied, a calculation was made on the distribution of species and for the reaction potentials for the oxidation/reduction of graphite, for the boiling/precipitation of liquid cesium, and for the extraction/precipitation of liquid monomeric $\mathrm{CsOH}$. Not all of the reaction potentials are included here because they tended to be similar. The cesium was added as a gaseous species and in each case amounted to $10^{-16} \mathrm{v} / \mathrm{v}$. Figures $5-18$ present the results. Distributions of species are plotted as the negative logarithm of the activity against temperature. Reaction potentials are also plotted against temperature.

Figure 5 is the equilibrium distribution for the $\mathrm{Ft}$. St. Vrain reactor. This environment is a start-up stoichiometry and is quite different from the rest, having free oxygen as a component. It is interesting to note that the Ft. St. Vrain distribution as computed agrees with the distribution as reported. In other words, the Ft. St. Vrain environment is in agreement with

TABLE III

\section{EXPERIMENTAL STEADY-STATE IMPURITY LEVELS IN PARTS PER MILLION ${ }^{24,25}$}

\begin{tabular}{|c|c|c|c|c|c|c|c|}
\hline Reactor & $\begin{array}{c}\text { Pressure } \\
(\mathbf{k P a})\end{array}$ & $\mathrm{H}_{2} \mathrm{O}$ & $\mathrm{CO}_{2}$ & $\mathbf{H}_{2}$ & $\mathrm{CO}$ & $\mathrm{CH}_{4}$ & $\mathbf{O}_{2}$ \\
\hline $\begin{array}{l}\text { Peach } \\
\text { Bottom }\end{array}$ & 2296 & $<0.5$ & --- & 9 & 0.5 & 0.6 &.-- \\
\hline AVR & 965 & 3 & 10 & 30 & 30 & --- & -.. \\
\hline Dragon & 2068 & 0.05 & $<0.02$ & 1.0 & 0.6 & 0.15 & $<0.02$ \\
\hline Ft. St. & 4826 & 150 & 15 & 1 & $0-2$ & $0-1.5$ & 20 \\
\hline
\end{tabular}


TABLE IV

COMPUTATIONAL STEADY-STATE IMPURITY LEVELS IN PARTS PER MILLION

\begin{tabular}{|c|c|c|c|c|c|c|}
\hline $\begin{array}{l}\text { Stoich- } \\
\text { iometry }\end{array}$ & $\mathrm{H}_{2} \mathrm{O}$ & $\mathrm{CO}_{2}$ & $\mathbf{H}_{2}$ & $\mathrm{CO}$ & $\mathrm{CH}_{4}$ & $\mathbf{O}_{2}$ \\
\hline I & 0.0121 & 0.0280 & 9.98 & 9.93 & 0.0016 & $2.99 \times 10^{-25}$ \\
\hline II & 22.5 & 43.3 & 470 & 391 & 3.54 & $4.63 \times 10^{-22}$ \\
\hline III & 2270 & 2400 & 6420 & 2930 & 652 & $2.56 \times 10^{-20}$ \\
\hline
\end{tabular}

equilibrium predictions as long as one assumes gas-gas equilibrium in the absence of gassolid equilibrium.

The calculations for the normal reactor stoichiometries are included in Figs. 6-15. The most obvious characteristic of these distributions is the tendency for the curves of the species $\mathrm{CO}, \mathrm{H}_{2}, \mathrm{H}_{2} \mathrm{O}, \mathrm{CO}_{2}$, and $\mathrm{CH}_{4}$ to cross one another in the vicinity of $550-700 \mathrm{~K}$. Above and below this temperature range, different patterns prevail, making this a transition region in the environment. This transition from low- to high-temperature behavior occurs in the range of reactor operation and confuses analysis of equilibrium predictions. Above this transition region, the stable components tend to be $\mathrm{CO}$ and $\mathrm{H}_{2}$.

These distributions indicate a simple behavior pattern for the fission-product cesium. In all cases, the dominant cesium species are seen to be $\mathrm{Cs}_{2}(\mathrm{OH})_{2}, \mathrm{CsOH}$, and cesium. No other species of cesium (at equilibrium) is reduced in abundance by less than several orders of magnitude. Three regimes are present in all environments. In the low-temperature regime, $\mathrm{Cs}_{2}(\mathrm{OH})_{2}$ is the dominant species. In the middle regime, $\mathrm{CsOH}$ is the most abundant species. In the high-temperature regime, elemental cesium is the dominant cesium species. Note that the low-temperature transition in the vicinity of $350 \mathrm{~K}$ from $\mathrm{Cs}_{2}(\mathrm{OH})_{2}$ to $\mathrm{CsOH}$ is insensitive to variations in stoichiometry. The transition from $\mathrm{CsOH}$ to cesium always occurs even though it may be outside the range of the calculation. This transition temperature is extremely sensitive to the oxidizing capacity of the atmosphere, increasing rapidly as the water and/or oxygen levels in the gas increase.

Figures 16, 17, and 18 show the carbon reaction potentials for the various environments analyzed. Figure 16 is the carbon reaction potential for the Ft. St. Vrain start-up stoichiometry. The environment is far from equilibrium because free oxygen is a component.

Figure 17 is the plot of the carbon reaction potential for the normal reactor stoichiometries. The Peach Bottom and the Dragon stoichiometries are positive over the entire reactor operating range, indicating a potential to precipitate carbon from the gaseous phase. The AVR stoichiometry is negative at high temperatures, indicating a potential for the gas phase to react with carbon. For this reason, the Peach Bottom and the Dragon stoichiometries are referred to as reducing environments, whereas the AVR is referred to as an oxidizing environment.

Figure 18 is a plot of the carbon reaction potentials for Stoichiometries I, II, and III. They are somewhat artificial in that they are made up from gas-solid mixtures that were equilibrated at $900 \mathrm{~K}$, and reaction potentials are all zero at that temperature. However, the slope of the curve is indicative of the chemical behavior of the environment, and in this respect they all are oxidizing environments.

A basic set of reactions that prevails in the presence of carbon may be taken as

$\mathrm{H}_{2} \mathrm{O}\langle\mathrm{g}\rangle=\mathrm{H}_{2}\langle\mathrm{~g}\rangle+0.5 \mathrm{O}_{2}\langle\mathrm{~g}\rangle$, 


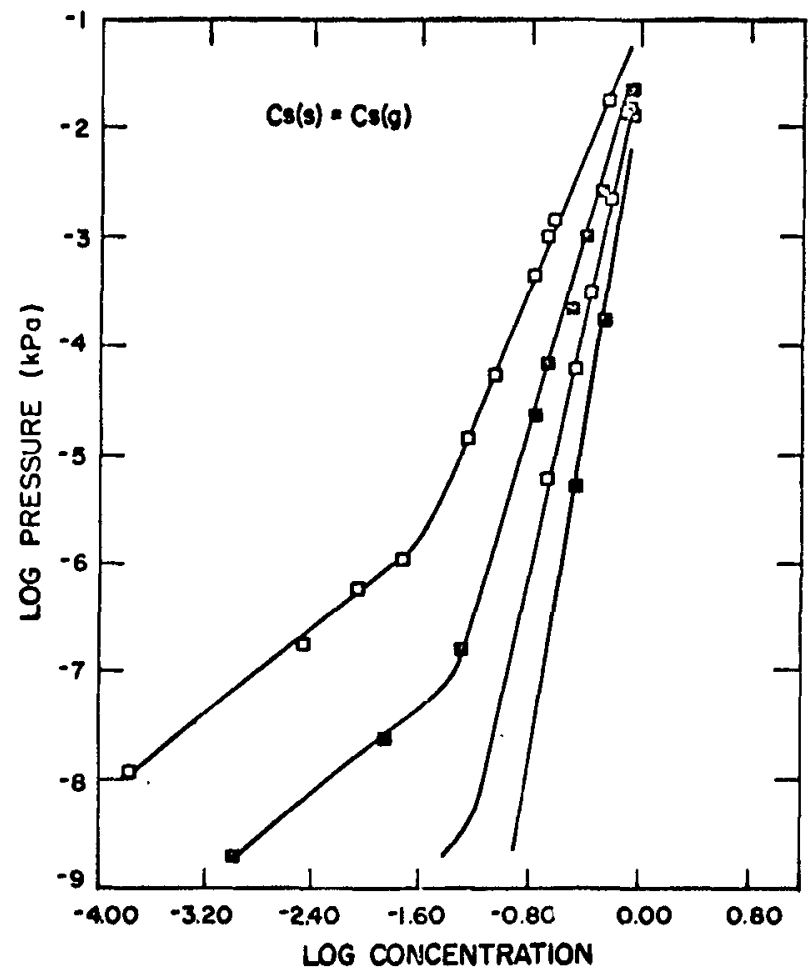

Fig. 4.

Parametric fit carried out by ISOT to the data of Milstead on reactor-grade TS-688 graphite.

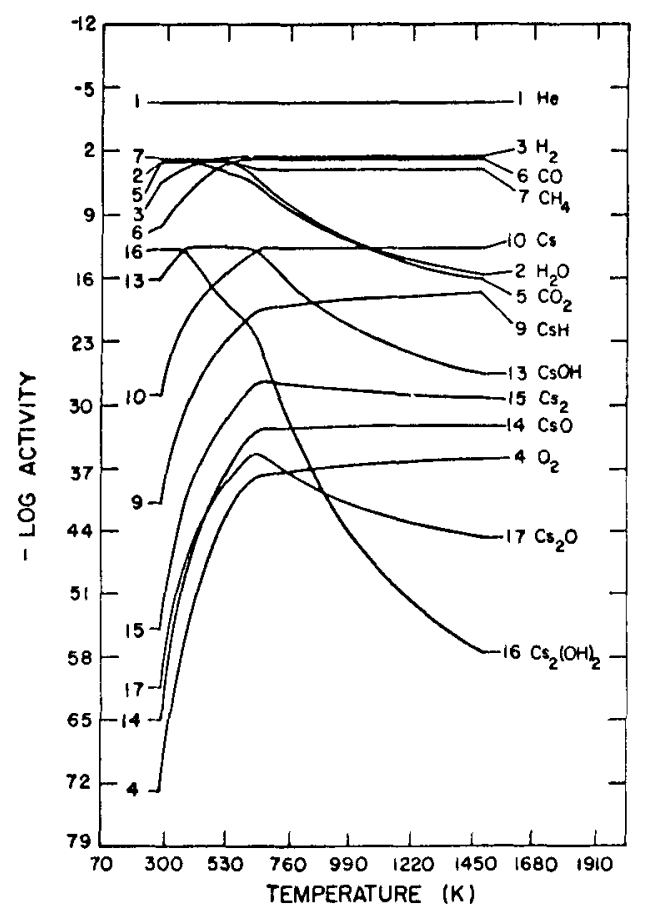

Fig. 6.

Distribution of species in the Dragon stoichiometry at $2068 \mathrm{kPa}$. No excess carbon present. Cesium present at $10^{-16} \mathrm{v} / \mathrm{v}$ gaseous.

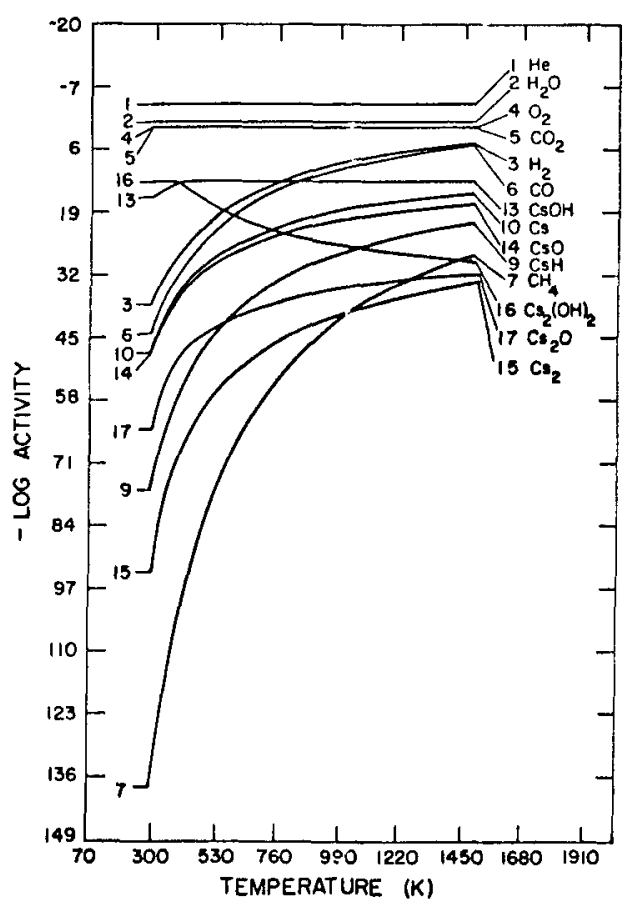

Fig. 5.

Distribution of species in the Ft. St. Vrain stoichiometry at $4826 \mathrm{kPa}$. No excess carbon present. Cesium present at $10^{-16} \mathrm{v} / \mathrm{v}$ gaseous.

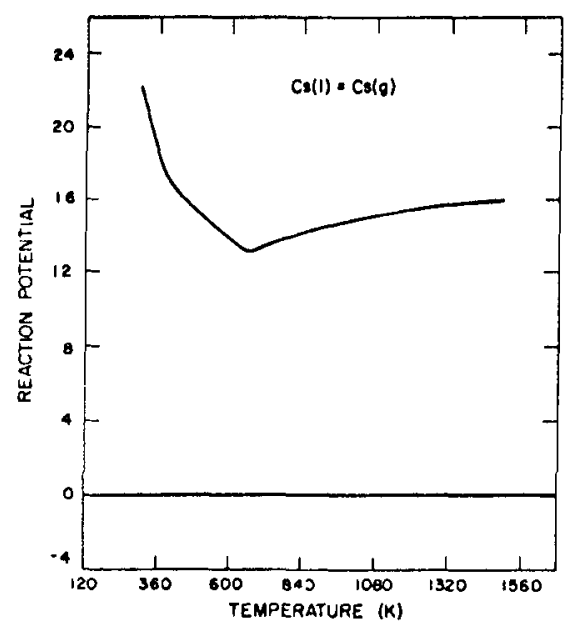

Fig. 7.

Cesium reaction potential in the Dragon stoichiometry at $2068 \mathrm{kPa}$. No excess carbon present. Cesium present at $10^{-16} \mathrm{v} / \mathrm{v}$ gaseous. 


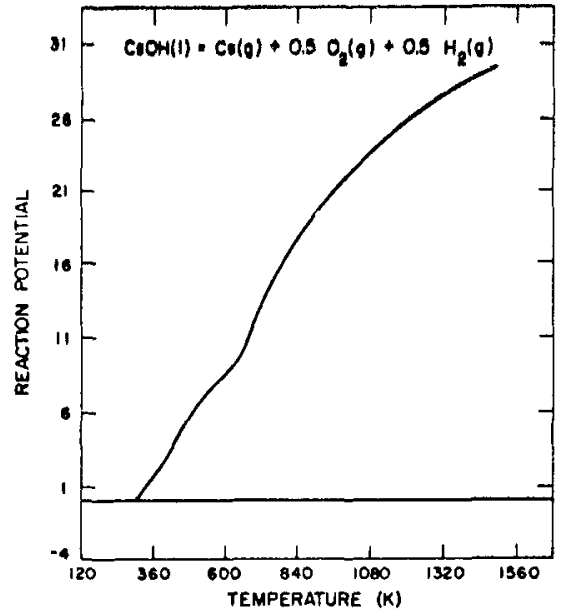

Fig. 8.

Cesium hydroxide reaction potential in the Dragon stoichiometry at $2068 \mathrm{kPa}$. No excess carbon present. Cesium present at $10^{-16} \mathrm{v} / \mathrm{v}$ gaseous.

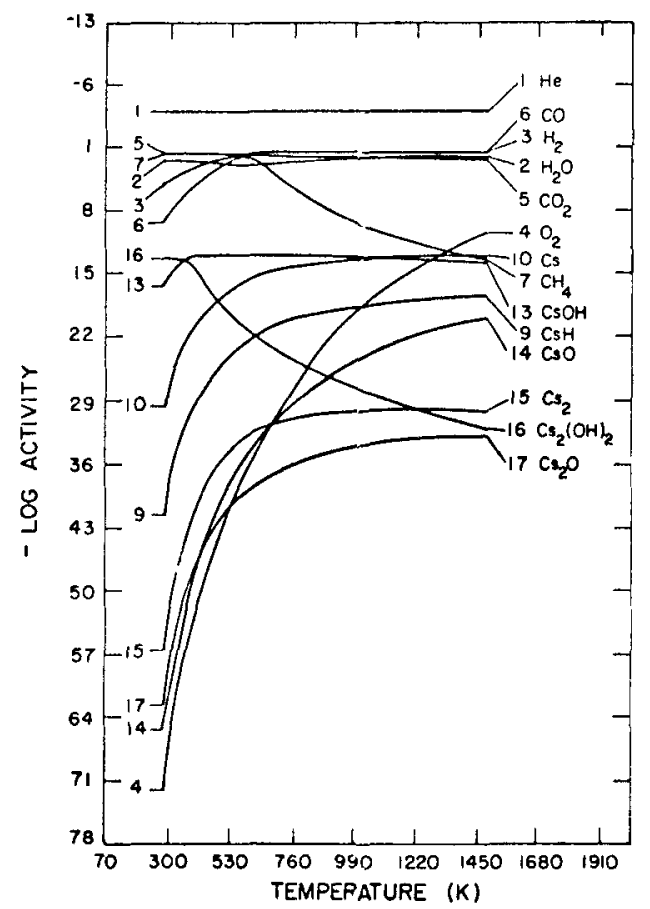

Fig. 10.

Distribution of species in the $A V R$ stoichiometry at $965 \mathrm{kPa}$. No excess carbon present. Cesium present at $10^{-16} \mathrm{v} / \mathrm{v}$ gaseous.

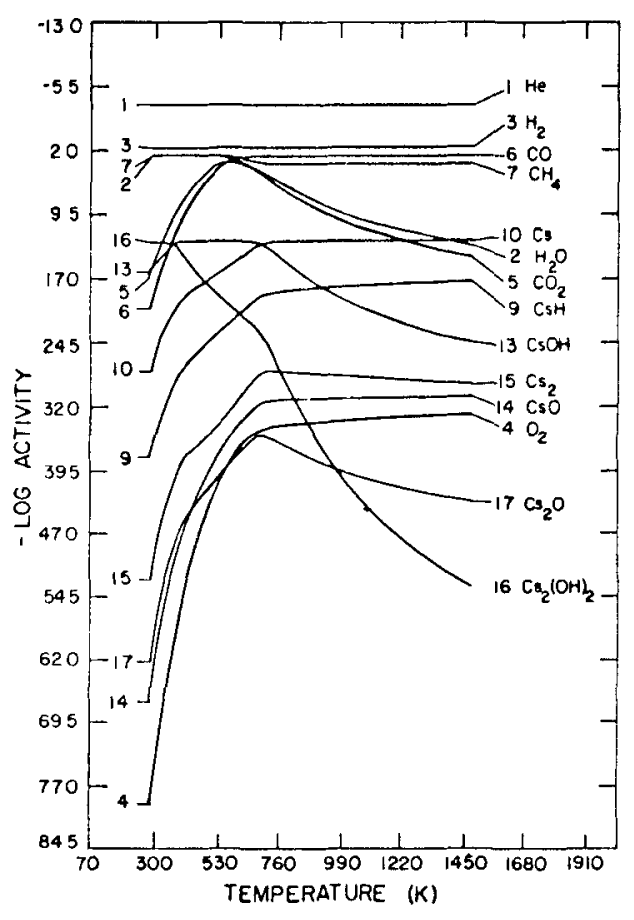

Fig. 9.

Distribution of species in the Peach Bottom stoichiometry at $2296 \mathrm{kPa}$. No excess carbon present. Cesium present at $10^{-16} \mathrm{v} / \mathrm{v}$ gaseous.

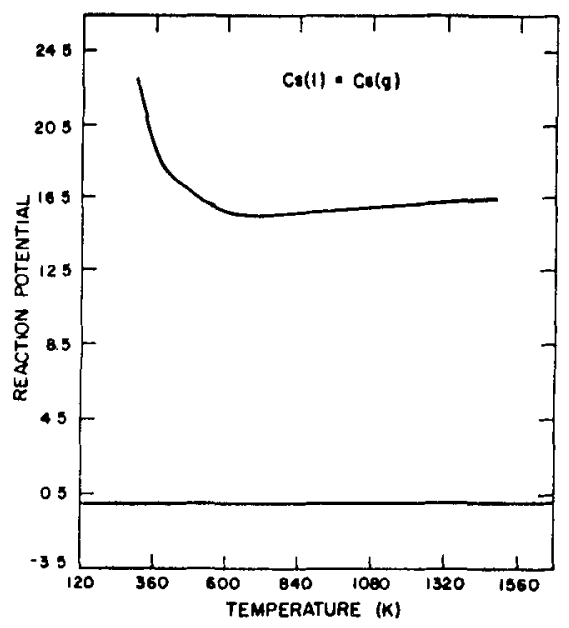

Fig. 11.

Cesium reaction potential in the $A V R$ stoichiometry at $965 \mathrm{kPa}$. No excess carbon present. Cesium present at $10^{-16} \mathrm{v} / \mathrm{v}$ gaseous. 


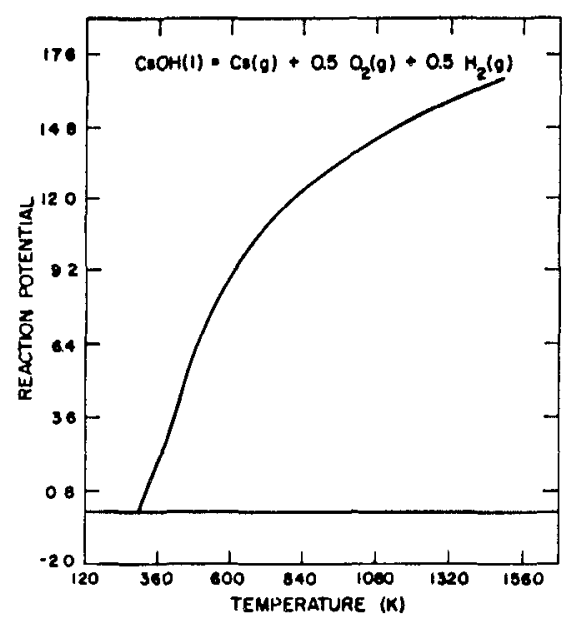

Fig. 12.

Cesium hydroxide reaction potential in the AVR stoichiometry at $965 \mathrm{kPa}$. No excess carbon present. Cesium present at $1^{-16} \mathrm{v} / \mathrm{v}$ gaseous.

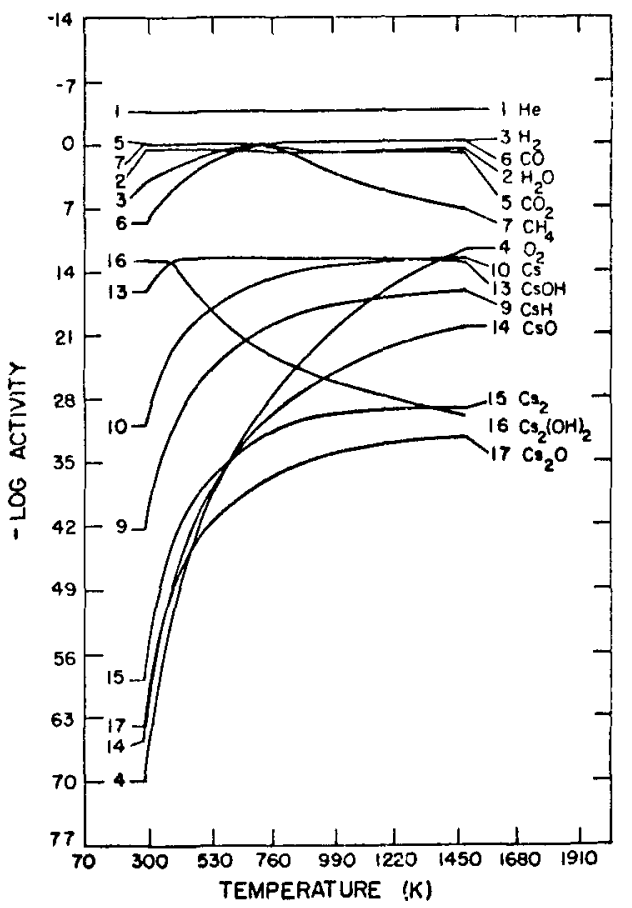

Fig. 14.

Distribution of species in Stoichiometry II at $5050 \mathrm{kPa}$. No excess carbon present. Cesium present at $10^{-16} \mathrm{v} / \mathrm{v}$ gaseous.

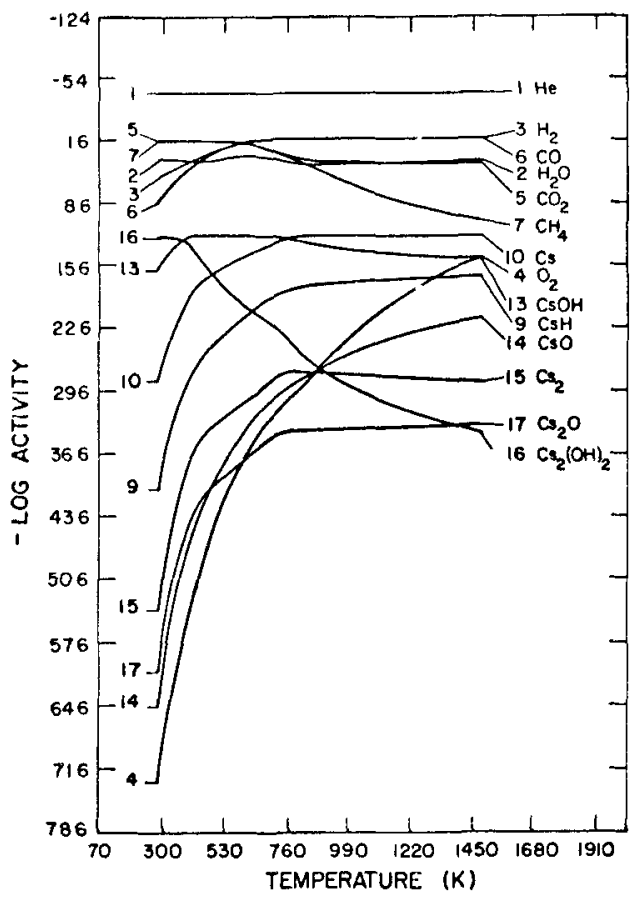

Fig. 13.

Distribution of species in Stoichiometry I at $5050 \mathrm{kPa}$. No excess carbon present. Cesium present at $10^{-16} \mathrm{v} / \mathrm{v}$ gaseous.

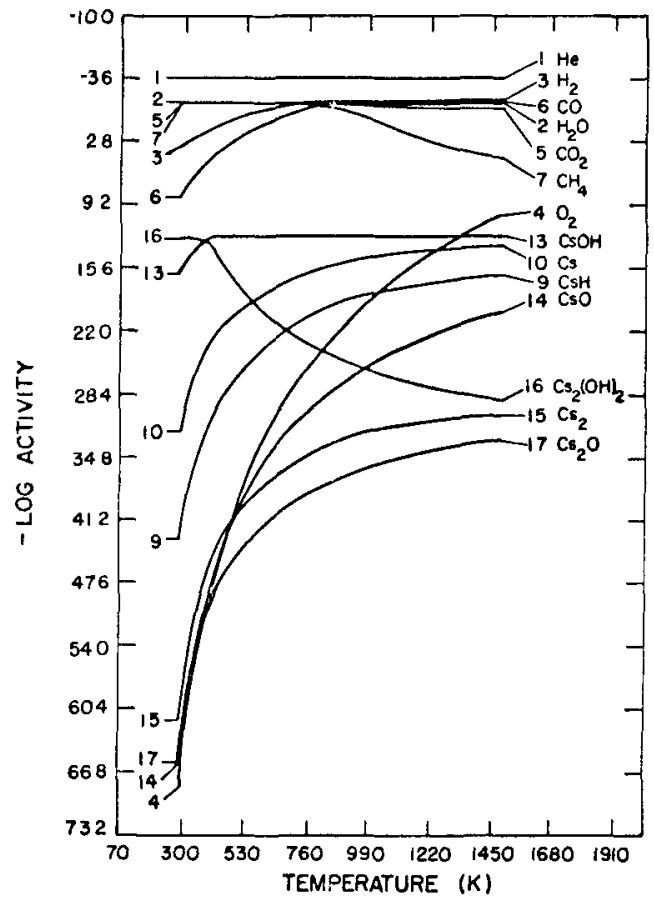

Fig. 15.

Distribution of species in Stoichiometry III at $5050 \mathrm{kPa}$. No excess carbon present. Cesium present at $10^{-1 \mathrm{~B}} \mathrm{v} / \mathrm{v}$ gaseous. 


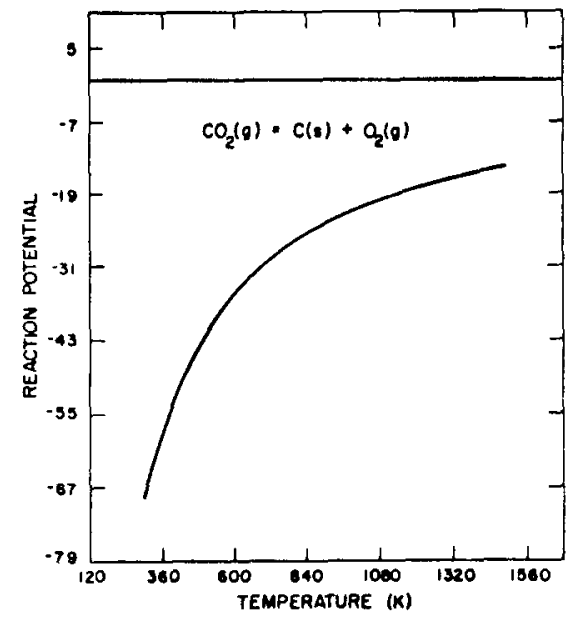

Fig. 16.

Carbon reaction potential in the Ft. St. Vrain stoichiometry at $4826 \mathrm{kPa}$.

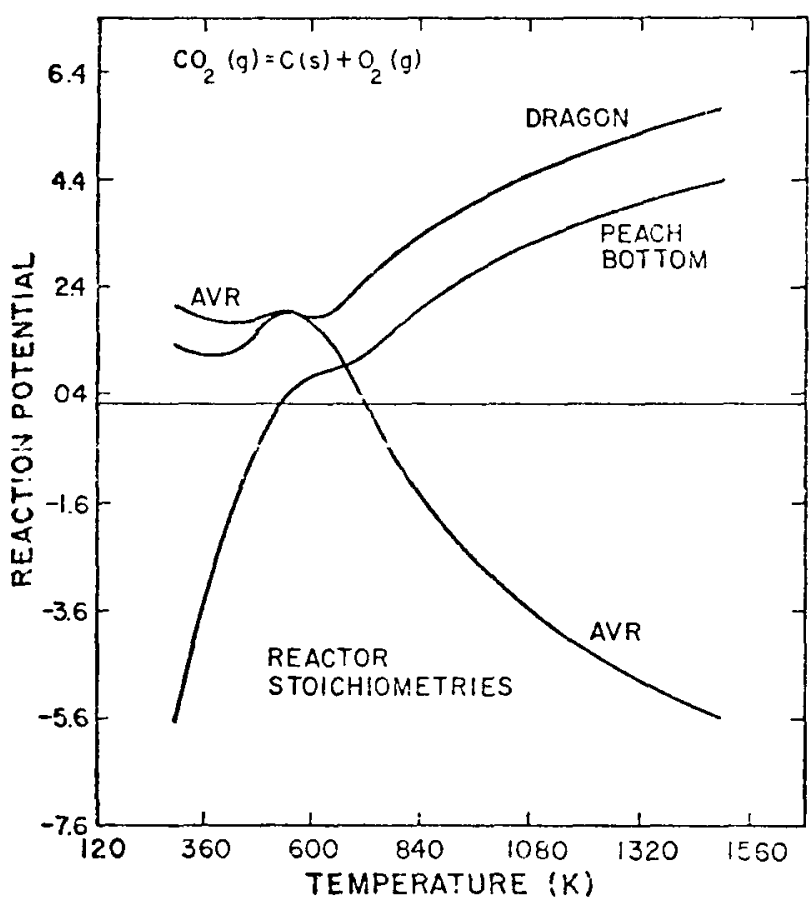

Fig. 17.

Carbon reaction potentials for the Dragon, Peach Bottom, and AVR stoichiometries.

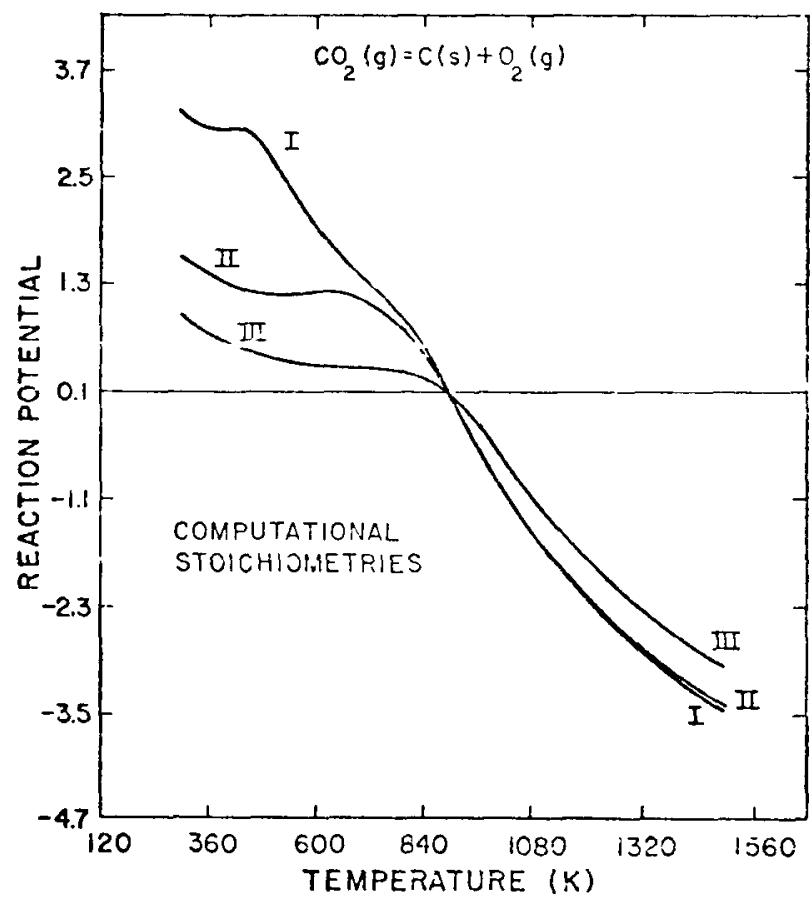

Fig. 18.

Carbon reaction potentials for Stoichiometries I, II, and III at $5050 \mathrm{kPa}$. 
$\mathrm{CO}_{2}\langle\mathrm{~g}\rangle=\mathrm{C}\langle\mathrm{s}\rangle+\mathrm{O}_{2}\langle\mathrm{~g}\rangle$,

$\mathrm{CO}\langle\mathrm{g}\rangle=\mathrm{C}\langle\mathrm{s}\rangle+0.5 \mathrm{O}_{2}\langle\mathrm{~g}\rangle$,

and

$\mathrm{CH}_{4}\langle\mathrm{~g}\rangle=\mathrm{C}\langle\mathrm{s}\rangle+2 \mathrm{H}_{2}\langle\mathrm{~g}\rangle$.

From this set we can write, assuming unit carbon activity,

$\mathrm{K}_{\mathrm{I}}=\frac{\mathrm{P}_{\mathrm{H}_{2}} \mathrm{P}^{1 / 2}{ }_{2}}{\mathrm{P}_{\mathrm{H}_{2} \mathrm{O}}}$,

$\mathrm{K}_{\text {II }}=\frac{\mathrm{P}_{\mathrm{O}_{2}}}{\mathrm{P}_{\mathrm{CO}_{2}}}$

$\mathrm{K}_{\text {III }}=\frac{\mathrm{P}_{0_{2}^{1 / 2}}^{1 / 2}}{\mathrm{P}_{\mathrm{CO}}}$

and

$\mathrm{K}_{\mathrm{IV}}=\frac{\mathrm{P}_{\mathrm{H}_{2}}^{2}}{\mathrm{P}_{\mathrm{CH}_{4}}}$

In the absence of carbon, or if one assumes that the gas-solid equilibria are inhibited, we have the reduced set

$$
\begin{aligned}
& \mathrm{H}_{2} \mathrm{O}\langle\mathrm{g}\rangle=\mathrm{H}_{2}\langle\mathrm{~g}\rangle+0.5 \mathrm{O}_{2}\langle\mathrm{~g}\rangle, \\
& \mathrm{CO}_{2}\langle\mathrm{~g}\rangle=\mathrm{CO}\langle\mathrm{g}\rangle+0.5 \mathrm{O}_{2}\langle\mathrm{~g}\rangle,
\end{aligned}
$$

and

$\mathrm{CO}\langle\mathrm{g}\rangle+2 \mathrm{H}_{2}\langle\mathrm{~g}\rangle=\mathrm{CH}_{4}\langle\mathrm{~g}\rangle+0.5 \mathrm{O}_{2}\langle\mathrm{~g}\rangle$.

For Eqs. (77)-(79) we may write

$$
\begin{aligned}
& \mathrm{K}_{\mathrm{A}}= \frac{\mathrm{P}_{\mathrm{H}_{2}} \mathrm{P}_{2}^{\mathrm{I} \mathrm{O}_{2}}}{\mathrm{P}_{\mathrm{H}_{2} \mathrm{O}}}, \\
& \mathrm{K}_{\mathrm{B}}=\frac{\mathrm{P}_{\mathrm{CO}_{\mathrm{O}}} \mathrm{P}_{2}^{1 / 2}}{\mathrm{P}_{\mathrm{CO}_{2}}},
\end{aligned}
$$


and

$\mathrm{K}_{\mathrm{C}}=\frac{\mathrm{P}_{\mathrm{CH}_{4}} \mathrm{P}_{\mathrm{O}_{2}}^{\mathrm{J} / 2}}{-\mathrm{P}_{\mathrm{CO}} \mathrm{P}_{\mathrm{H}_{2}}^{2}}$.

The second set of equilibrium relations determines the distribution of species in the gas of the coolant channels, while both sets of equilibrium relations define the reaction potentials. In this case, it is important to remember that, in general, the first set is not satisfied. We can thus write a third set

$\mathrm{K}_{\mathrm{I}}^{\prime}=\frac{{ }_{\mathrm{H}_{2}{ }^{\mathrm{P}_{2}} \mathrm{O}_{2}}}{\mathrm{P}_{\mathrm{H}_{2} \mathrm{O}}}$.

$\mathrm{K}_{\mathrm{II}}^{\prime}=\frac{\mathrm{P}_{\mathrm{O}_{2}}}{{ }_{\mathrm{PO}_{2}}}$,

$\mathrm{K}_{\text {III }}^{\prime}=\frac{\mathrm{P}_{\mathrm{O}_{2}}^{1 / 2}}{\mathrm{P}_{\mathrm{CO}}}$,

and

$\mathrm{K}_{\mathrm{IV}}^{\prime}=\frac{\mathrm{P}_{\mathrm{H}_{2}}^{2}}{\mathrm{P}_{\mathrm{CH}_{4}}}$,

where the prime indicates that the ratios in the third set have been computed from the distribution of the species that results when the second set of equations is solved. By definition

$R=\frac{K_{I I I}}{K^{\prime} I I I}$

is a reaction constant (see Sec. IV). By combination of Eqs. (75), (80), (82), and (85), we get

$\mathrm{R}=\mathrm{R}_{\mathrm{o}}\left(\frac{\mathrm{P}_{\mathrm{CO}}}{\mathrm{P}_{\mathrm{H}_{2}}}\right)^{1 / 2}\left(\frac{\mathrm{P}_{\mathrm{CH}_{4}}}{\mathrm{P}_{\mathrm{H}_{2} \mathrm{O}}}\right)^{1 / 2}$,

where the factor $R_{0}$ is given by

$R_{0}=\frac{K_{I I I}}{\left(K_{A} K_{C}\right)^{1 / 2}}$.

The logarithm of $\mathrm{R}$ gives the reaction potential of the coolant gas with respect to the carbon. Letting 
and

$\theta_{0}=\log \left(R_{0}\right)$,

we have

$\theta=\theta_{0}+\frac{1}{2} \log \left[\frac{\mathrm{P}_{\mathrm{CO}}}{\mathrm{P}_{\mathrm{H}_{2}}}\right]+\frac{1}{2} \log \left[\frac{\mathrm{CH}_{4}}{\mathrm{P}_{\mathrm{H}_{2} \mathrm{O}}}\right]$

as a total reaction potential of the gas toward the carbon.

The constant $\theta_{0}$ as a function of temperature is tabulated in Table $\mathrm{V}$ and plotted in Fig. 19. It varies by one log cycle over the $600-1200 \mathrm{~K}$ range. In view of the large changes in the equilibrium constants, this parameter is remarkably constant. The remainder of the reaction potential is written in terms of the species $\mathrm{CO}, \mathrm{H}_{2}, \mathrm{CH}_{4}$, and $\mathrm{H}_{2} \mathrm{O}$.

In what follows, we will suggest that, in an HTGR-like environment, the species that are present in abundance are $\mathrm{CO}$ and $\mathrm{H}_{2}$. The species that may or may not be present in abundance are $\mathrm{CH}_{4}, \mathrm{H}_{2} \mathrm{O}$, and $\mathrm{CO}_{2}$. In this sense, the $\mathrm{CO}$ and $\mathrm{H}_{2}$ are referred to as components, while the $\mathrm{CH}_{4}, \mathrm{H}_{2} \mathrm{O}$, and $\mathrm{CO}_{2}$ are referred to as constituents.

When the reaction potential is written as in Eq. (92), not only is the expression independent of pressure, but the form involves a ratio of components $\left(\mathrm{CO}\right.$ and $\left.\mathrm{H}_{2}\right)$ and a ratio of constituents $\left(\mathrm{H}_{2} \mathrm{O}\right.$ and $\left.\mathrm{CH}_{4}\right)$ that interact in a special way. A stoichiometry made up of these components will show a balanced behavior with respect to the formation of these constituents. In this context, balanced behavior simply means that the concentrations of water and methane are nearly equal. To illustrate, the distributions are computed for three stoichiometries made up from the components $\mathrm{CO}$ and $\mathrm{H}_{2}$. The resultant distributions are plotted in Figs. 20, 21, and 22. Over the high-temperature range, the water and methane activities are nearly equal. As the ratio of $\mathrm{H}_{2} / \mathrm{CO}$ becomes large, the $\mathrm{CH}_{4} / \mathrm{H}_{2} \mathrm{O}$ ratio approaches 1.0, even though the values of the $\mathrm{CH}_{4}$ and $\mathrm{H}_{2} \mathrm{O}$ activities fall by orders of magnitude. This balanced behavior means that the reaction potential for an environment made up of components will be due solely to the components. To further illustrate the point, Fig. 23 shows that when reaction potentials are plotted for a series of initial $\mathrm{H}_{2} / \mathrm{CO}$ ratios, the shape of $\theta_{0}$ will be recovered in the high-temperature region of the environment. As before, this implies that

\section{TABLE V}

\section{VALUES OF THE CONSTANT FOR THE CARBON REACTION POTENTIAL}

\begin{tabular}{rrr}
$\underline{\mathbf{T}(\mathbf{K})}$ & $\underline{\mathbf{R}_{\circ}}$ & $\underline{\theta_{0}}$ \\
\cline { 3 - 4 } & & 1.36 \\
700 & 6.97 & 0.843 \\
800 & 4.12 & 0.615 \\
900 & 2.76 & 0.442 \\
1000 & 2.03 & 0.307 \\
1100 & 1.58 & 0.198 \\
1200 & 1.29 & 0.110
\end{tabular}




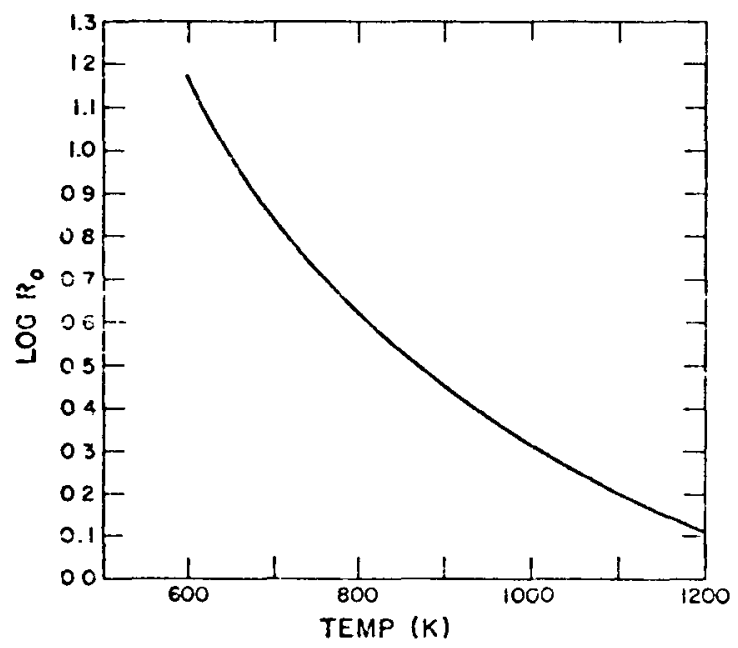

Fig. 19.

Plot of the constant, $\theta_{1}$, for the carbon reaction potential as derived in the text.

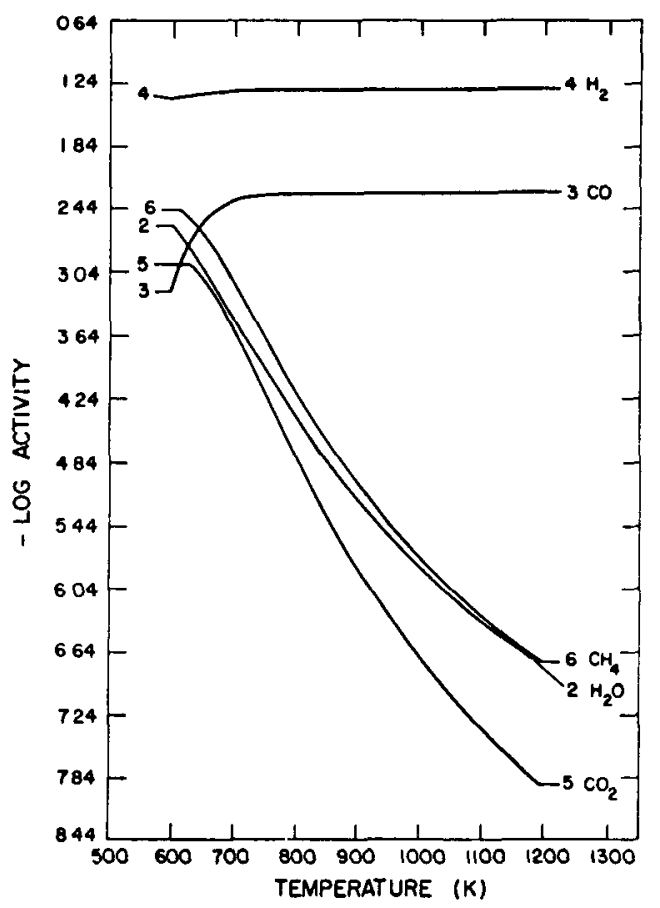

Fig. 21.

Distribution of species for a neutral stoichiometry of $10 \mathrm{ppm} \mathrm{H}_{2}$ and $1 \mathrm{ppm} \mathrm{CO}$ at $5050 \mathrm{kPa}$. No excess carbon present.

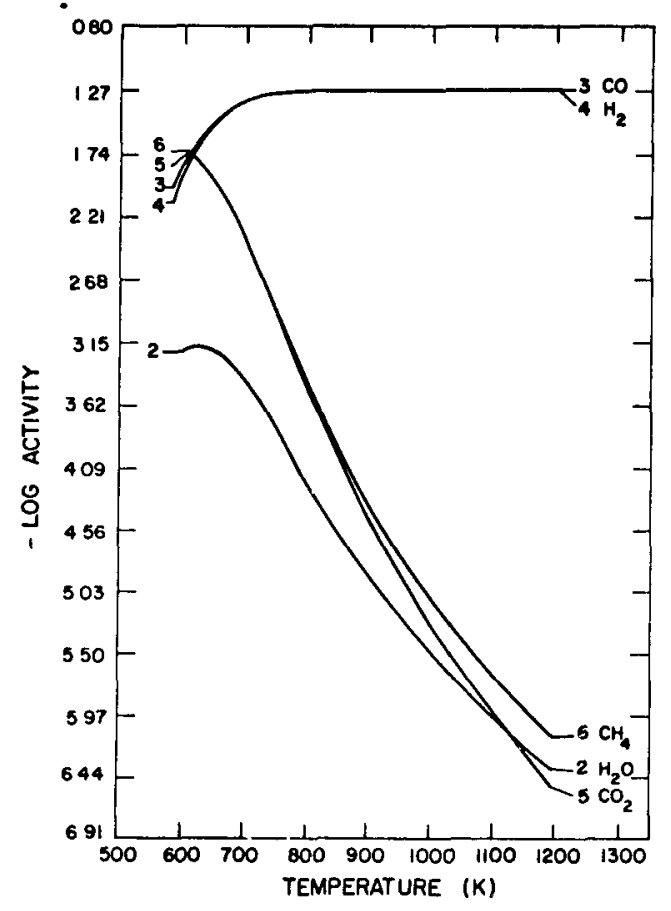

Fig. 20.

Distribution of species for a neutral stoichiometry of $10 \mathrm{ppm}_{2}$ and $10 \mathrm{ppm} \mathrm{CO}$ at $5050 \mathrm{kPa}$. No excess carbon present.

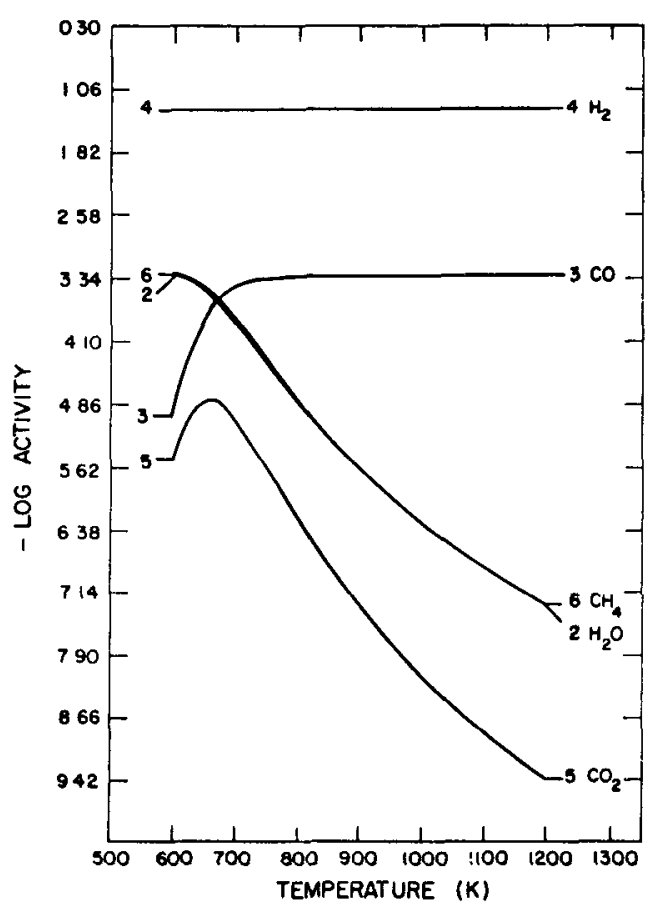

Fig. 22.

Distribution of species for a neutral stoichiometry of $10 \mathrm{ppm}_{2}$ and $0.1 \mathrm{ppm} \mathrm{CO}$ at $5050 \mathrm{kPa}$. No excess carbon present. 
the $\mathrm{CH}_{4} / \mathrm{H}_{2} \mathrm{O}$ ratio is balanced, since the reaction potential is due solely to the initial $\mathrm{H}_{2} / \mathrm{CO}$ ratio.

To illustrate the effect of the $\mathrm{CH}_{4} / \mathrm{H}_{2} \mathrm{O}$ ratio on the carbon reaction potential, Figs. 24, 25, and 26 show plots of the reaction potential in stoichiometries wherein excess $\mathrm{CH}_{4} \mathrm{or}_{2} \mathrm{O}$ has been added. Note the large change in reaction potential arising from relatively small additions of water and methane compared with the effects due to the components.

The $\mathrm{H}_{2} \mathrm{O} / \mathrm{CH}_{4}$ ratio has a predictably large effect on the reaction potential of the gas. Because the $\mathrm{H}_{2}$ and $\mathrm{CO}$ are components of the gas, their concentrations are not temperature-dependent in the high-temperature region. Under balanced conditions, both the water and methane will fall 4 to 6 orders of magnitude as the temperature is raised to $1200 \mathrm{~K}$. This balanced decrease can take place only if the input stoichiometry is balanced with respect to the $\mathrm{H}_{2} \mathrm{O}$ and $\mathrm{CH}_{4}$. If one of the constituents is present in excess, its concentration will limit at the temperature corresponding to this excess value. The concentration of the other constituent, not being limited, will fall off even faster. The reaction potential is thus unbalanced above this temperature. This large dependence of reaction potential upon minor concentration levels implies that computational analysis of reported stoichiometries will have large associated uncertainties. By way of illustration, it is possible to compute the reaction potential for the Peach Bottom stoichiometry with the reported levels of $\mathrm{H}_{2} \mathrm{O}$ and $\mathrm{CH}_{4}$ reversed. If the $\mathrm{CH}_{4} / \mathrm{H}_{2} \mathrm{O}$ ratio were $0.5 / 0.6$ instead of the reported 0.6/0.5, the distribution plotted in Fig. 27 would result. The carbon reaction potentials for the normal and the reverse Peach Bottom stoichiometries are plotted in Fig. 28. The effect upon the reaction potential is radical for a seemingly insignificant change in stoichiometry, and implies that it may be difficult to deduce much about the carbon reaction potential of an environment by sampling.

With a stoichiometry that is reasonably close to a steady-state HTGR operating environment, the $\mathrm{CO}_{2}$ and $\mathrm{H}_{2} \mathrm{O}$ behave similarly. Therefore, at high temperatures the expression

$\mathrm{E}=\mathrm{CH}_{4}-\mathrm{H}_{2} \mathrm{O}-\mathrm{CO}_{2}$

almost always has the same sign as the carbon reaction potential. To date, the calculations suggest that the low-temperature carbon reaction potential is almost always small and positive. These two pieces of information suggest that the sign of the carbon reaction potential in an HTGR environment can be deduced by observation.

\section{THE GAS IN THE GRAPHITE}

When the gas from the coolant channel enters the graphite, it is assumed that it will come to equilibrium with the free carbon. This, in turn, will cause a change in the composition of the gas phase. In general, the change is difficult to predict because the carbon may be oxidized or reduced by either the oxygen or the hydrogen reactions. Correlations seem to depend upon the shape of the carbon reaction potential and upon whether the crossover point for the reaction potential occurs in the region of high- or low-temperature behavior.

Figures 29,30, and 31 indicate the kind of changes that occur when the gas in the coolant channel enters the graphite and equilibrates with the solid carbon. In the high-temperature region, the response of the $\mathrm{CsOH}$ and of the $\mathrm{O}_{2}$ correlates with the reaction potential. When the graphite reaction potential is positive, the changes tend to produce higher partial pressures of oxygen. This, in turn, forces the activity of $\mathrm{CsOH}$ to increase also. When the graphite reaction potential is negative, the oxygen partial pressure decreases upon equilibration with the graphite and the partial pressure of the $\mathrm{CsOH}$ decreases accordingly. At low temperatures, no correlation seems possible. 


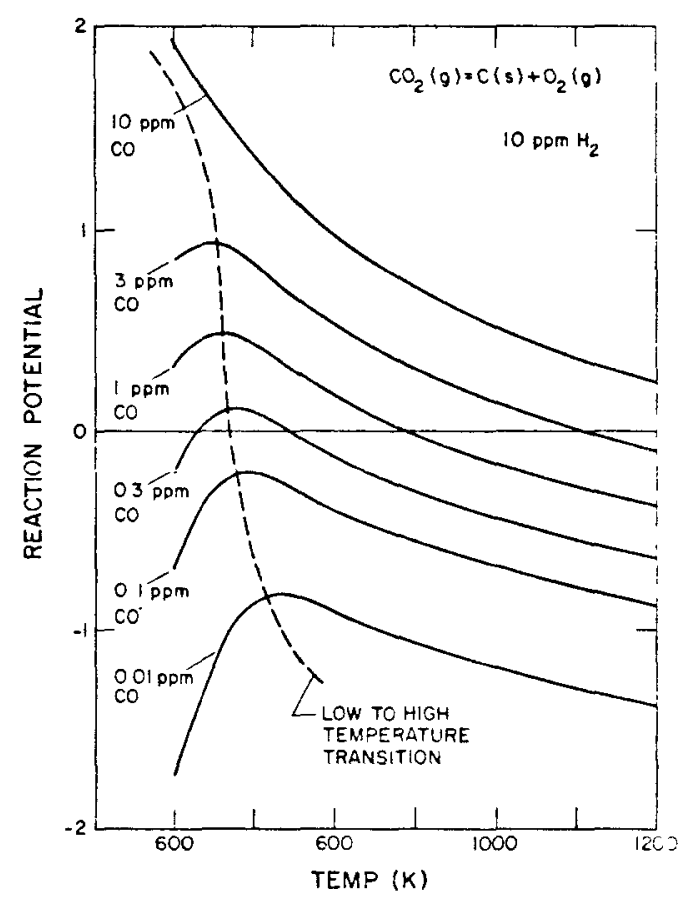

Fig. 23.

Carbon reaction potential in various neutral stoichiometries at $5050 \mathrm{kPa}$ for different starting ratios of $\mathrm{H}_{2}$ and $\mathrm{CO}$. No excess carbon present.

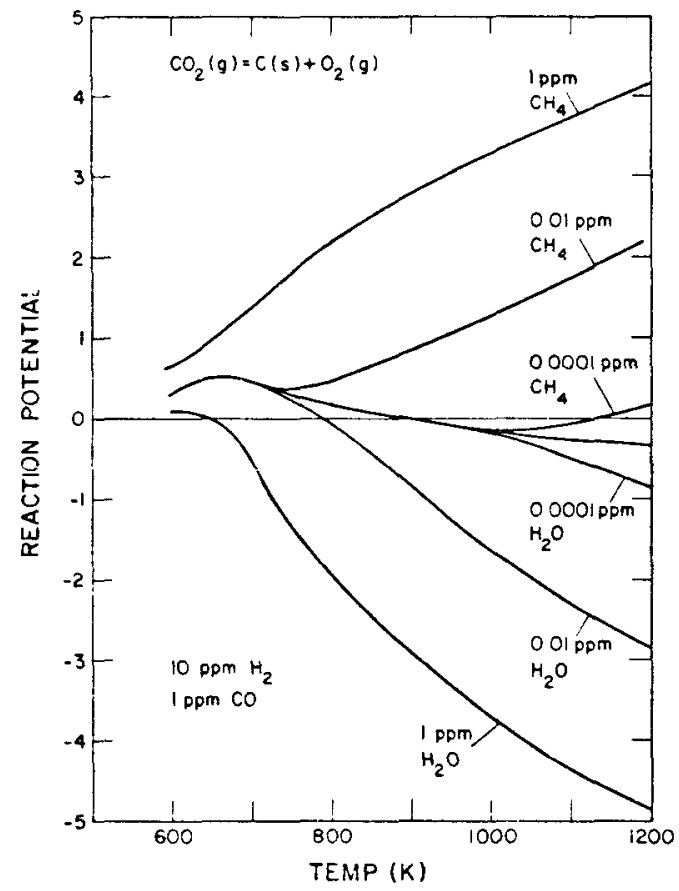

Fig. 25.

Carbon reaction potential in a neutral stoichiometry of $10 \mathrm{ppm} \mathrm{H}_{2}$ and $1 \mathrm{ppm} \mathrm{CO}$ at $5050 \mathrm{kPa}$. $\mathrm{CH}_{4}$ or $\mathrm{H}_{2} \mathrm{O}$ added.

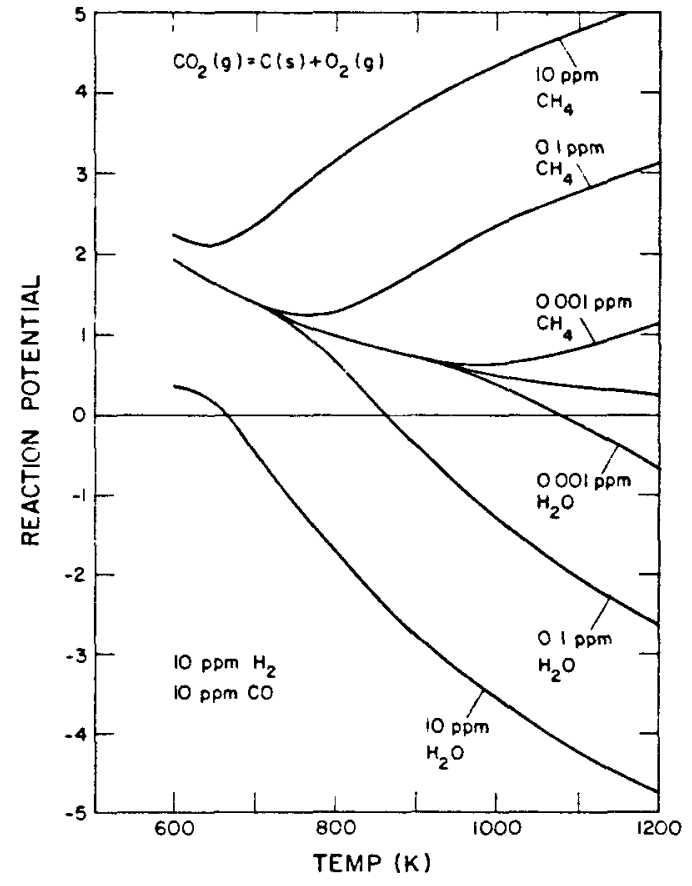

Fig. 24.

Carbon reaction potential in a neutral stoichiometry of $10 \mathrm{ppm} \mathrm{H}_{2}$ and $10 \mathrm{ppm} \mathrm{CO}$ at $5050 \mathrm{kPa}$. $\mathrm{CH}_{4}$ or $\mathrm{H}_{2} \mathrm{O}$ added.

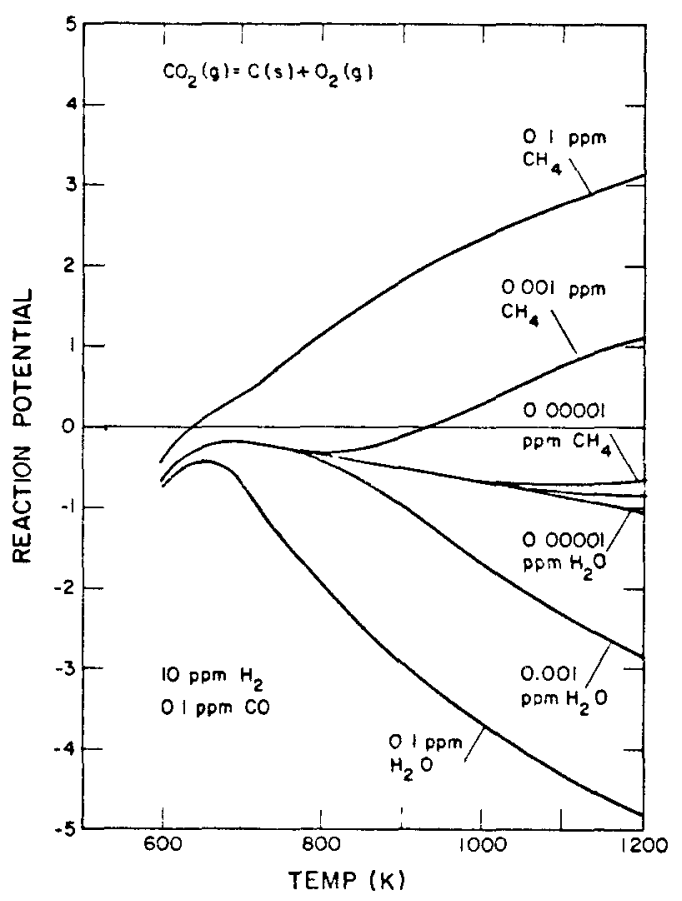

Fig. 26.

Carbon reaction potential in a neutral stoichiometry of $10 \mathrm{ppm} \mathrm{H}_{2}$ and $0.1 \mathrm{ppm} \mathrm{CO}$ at $5050 \mathrm{kPa}$. $\mathrm{CH}_{4}$ or $\mathrm{H}_{2} \mathrm{O}$ added. 


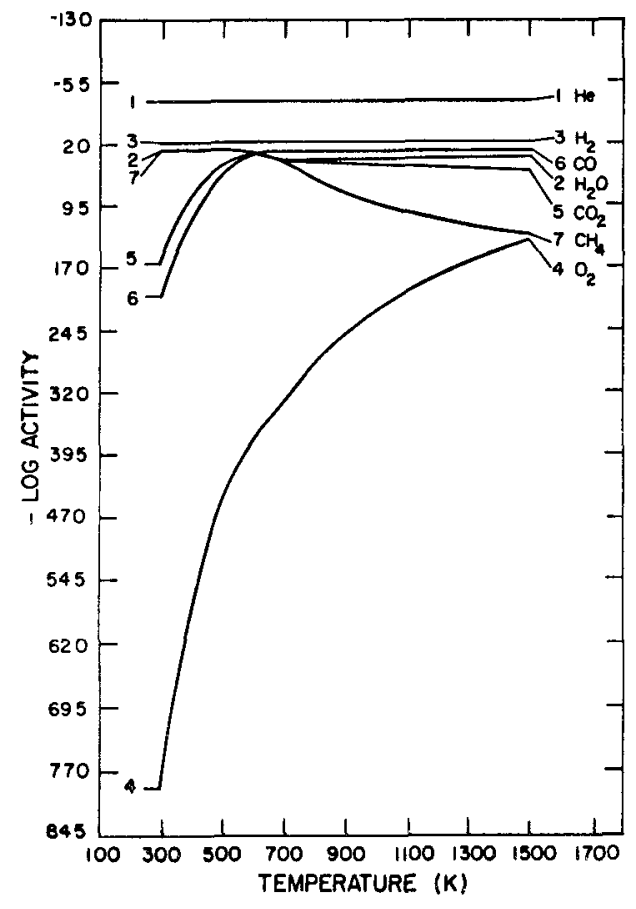

Fig. 27.

Distribution of species in the reverse Peach Bottom stoichiometry at $2296 \mathrm{kPa}$. No excess carbon present.

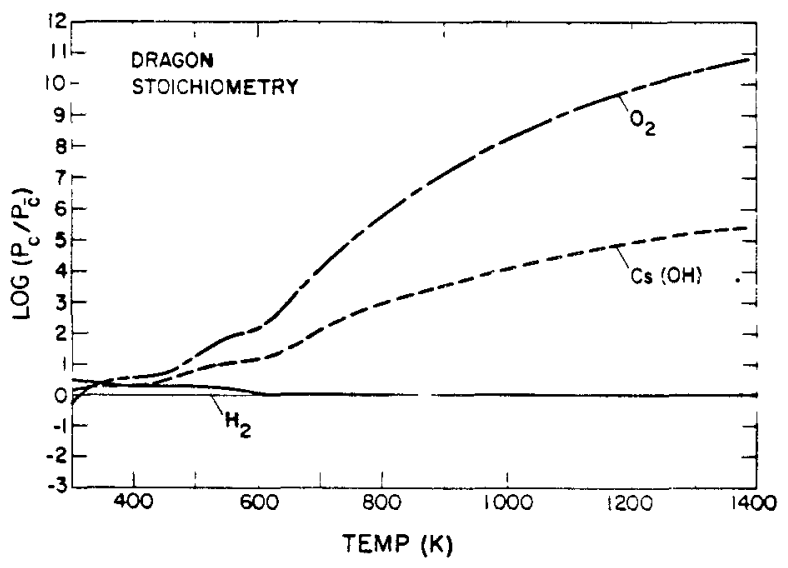

Fig. 29.

Change in the distribution of species relating to the $\mathrm{CsOH}$ activity in the Dragon stoichiometry at 2068 caused by the introduction of free carbon. $\left(P_{\mathrm{c}} / P_{\mathrm{c}}\right)$ is the ratio of the gas pressure in the presence of carbon to the pressure in the absence of carbon.

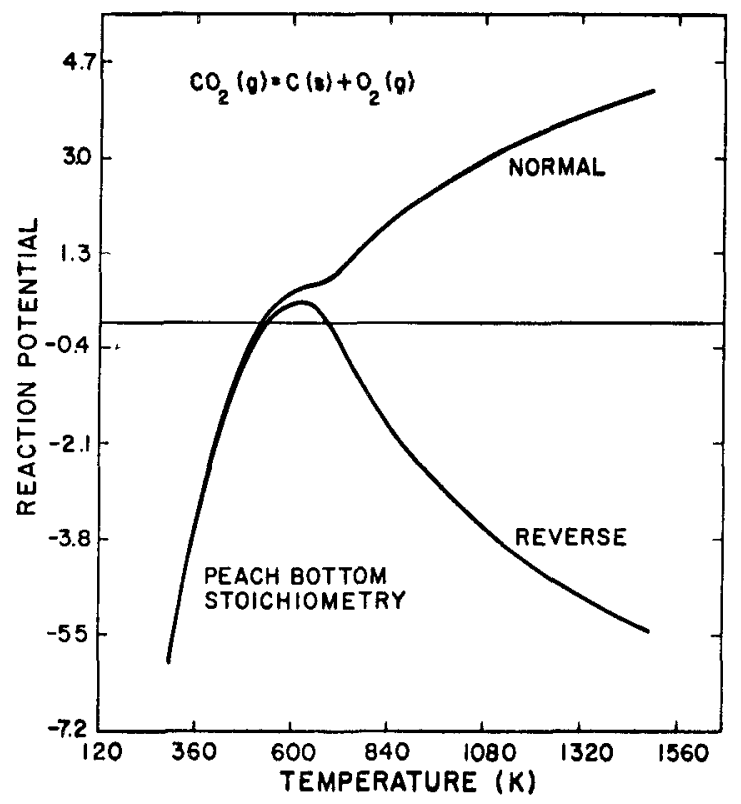

Fig. 28.

Carbon reaction potential in the normal and the reverse Peach Bottom stoichiometries at $2296 \mathrm{kPa}$.

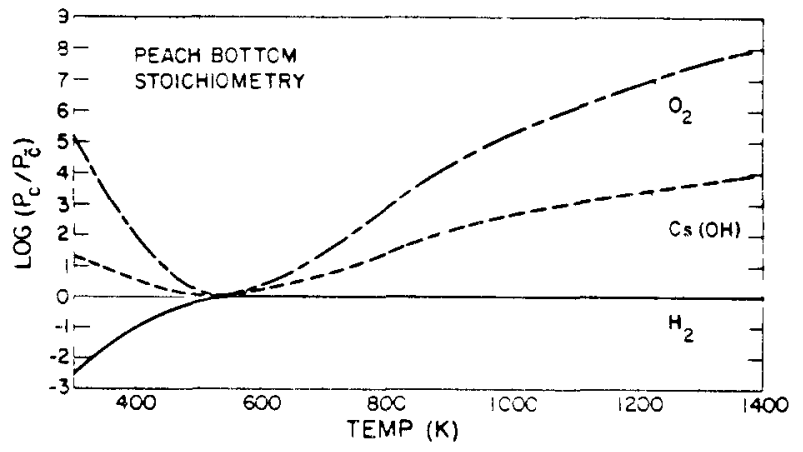

Fig. 30.

Change in the distribution of species relating to the $\mathrm{CsOH}$ activity in the Peach Bottom stoichiometry at $2296 \mathrm{kPa}$ caused by the introduction of free carbon. $\left(P_{\mathrm{c}} / P_{\overrightarrow{\mathrm{c}}}\right)$ is the ratio of the gas pressure in the presence of carbon to the pressure in the absence of carbon. 


\section{THE GAS IN THE PRESENCE OF SURF ACE PHASES}

To model the gas in the presence of surface phases, calculations are made with and without solid carbon present. The plots are very similar, indicating that the effect of carbon on the cesium equilibria is small. The cesium partial pressure as computed for the isotherm at low temperatures represents a considerable extrapolation of the parametric model and should not be interpreted quantitatively.

Figures 32-35 show computed distributions for Dragon, Peach Bottom, AVR, and Stoichiometry I in the absence of carbon. For all the environments except the AVR, the Cs/ $\mathrm{CsOH}$ crossover point is in the range of $650-750 \mathrm{~K}$. AVR is oxidizing with respect to the cesium reactions, since the $\mathrm{Cs} / \mathrm{CsOH}$ transition for this stoichiometry is some $350 \mathrm{~K}$ above that of the other environments. The distributions for Stoichiometries II and III are not shown; the $\mathrm{CsOH} / \mathrm{Cs}$ crossover temperature is well above $1500 \mathrm{~K}$ due to the oxidizing capacity of these environments.

Figures 36-38 show distributions computed for Dragon, Peach Bottom, and AVR in the presence of carbon. For all environments including AVR, the $\mathrm{Cs} / \mathrm{CsOH}$ crossover point is in the $650-750 \mathrm{~K}$ range. The oxidizing potential of the AVR environment has been reduced by reaction with the graphite. The distributions for Stoichiometries I, II, and III are not shown, but are similar to that for AVR. This is predictable, because the introduction of excess carbon into an environment with a negative carbon reaction potential will cause the activity of $\mathrm{O}_{2}$ to decrease.

Figure 39 is a plot of the activity of a typical cesium isotherm. Total changes are very slight, ranging from parts per thousand in the absence of carbon to parts per million in the presence of carbon. As the graph indicates, an increase in temperature above $1500 \mathrm{~K}$ will initiate an equilibrium transfer of cesium from the graphite to the gas phase.

\section{DEPRESSURIZATION}

The effect of depressurization upon the equilibrium distribution of cesium species is almost negligible in all phases. The worst-case calculation is a depressurization event with adsorbed cesium present, because it could cause the cesium on the surface to be dumped into the gas phase. Two such calculations are presented in Figs. 40 and 41 . The calculations are carried out at $1200 \mathrm{~K}$. For the Peach Bottom depressurization, the pressure limits are 2296-202 kPa. For the Stoichiometry I depressurization, the pressure limits are 5050-202 $\mathrm{kPa}$, The cesium is present at $0.01 \%$ of monolayer coverage. In both cases, the distribution of species is only slightly affected by the pressure change. The isotherms are also insensitive to the depressurization, the change representing a variation of only one part in $10^{7}$.

\section{STEAM INGRESS}

Steam ingress will affect the distribution of cesium species more than it will affect the cesium isotherm. The worst-case calculation is a steam-ingress event with adsorbed cesium present, because the cesium on the surface could be dumped into the gas phase. A calculation was made on Stoichiometry I over the range $300-1500 \mathrm{~K}$ with $10000 \mathrm{ppm}_{2} \mathrm{O}$ present. The cesium is present at $0.01 \%$ of monolayer coverage. The equilibrium distribution, shown in Fig. 42, indicates that monomeric cesium hydroxide, $\mathrm{CsOH}$, becomes the most abundant cesium species by many orders of magnitude. However, the cesium isotherm changes by only a few per cent over the range of reactor operation, as indicated by Fig. 43. Since the isotherm is stable under the calculated ingress, the major effect would be one related to the 


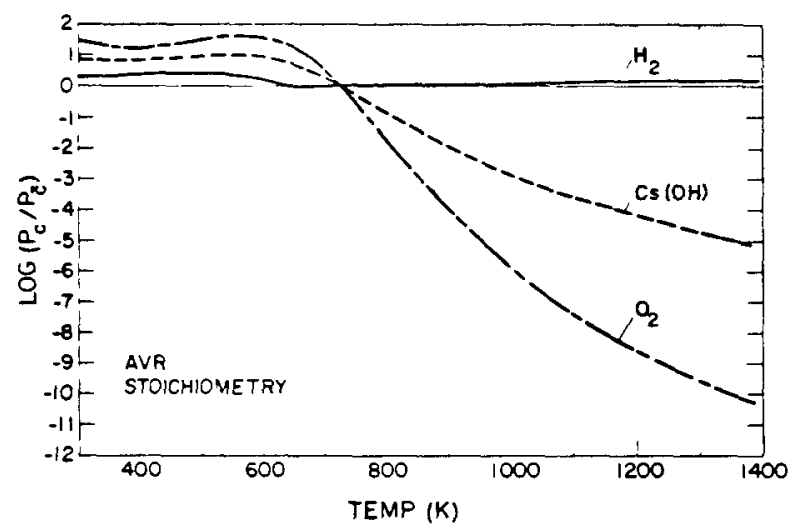

Fig. 31.

Change in the distribution of species relating to the CsOH activity in the AVR stoichiometry at $965 \mathrm{kPa}$ caused by the introduction of free carbon. $\left(P_{\mathrm{c}} / P_{\overline{\mathrm{c}}}\right)$ is the ratio of the gas pressure in the presence of carbon to the pressure in the absence of carbon.

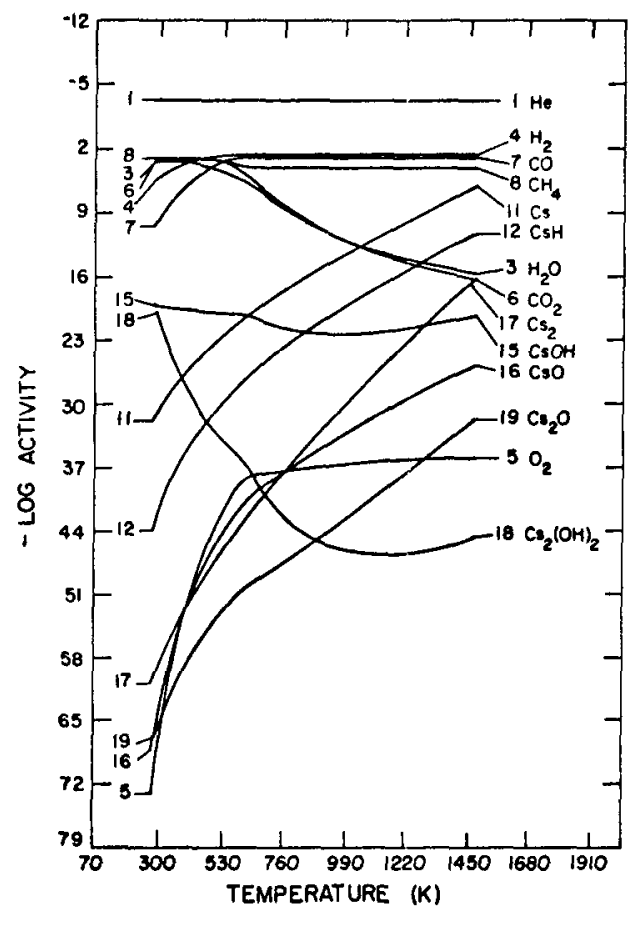

Fig. 32.

Distribution of species in the Dragon stoichiometry at $2068 \mathrm{kPa}$. No excess carbon present for gas reactions. Cesium present as a $0.01 \%$ isotherm.

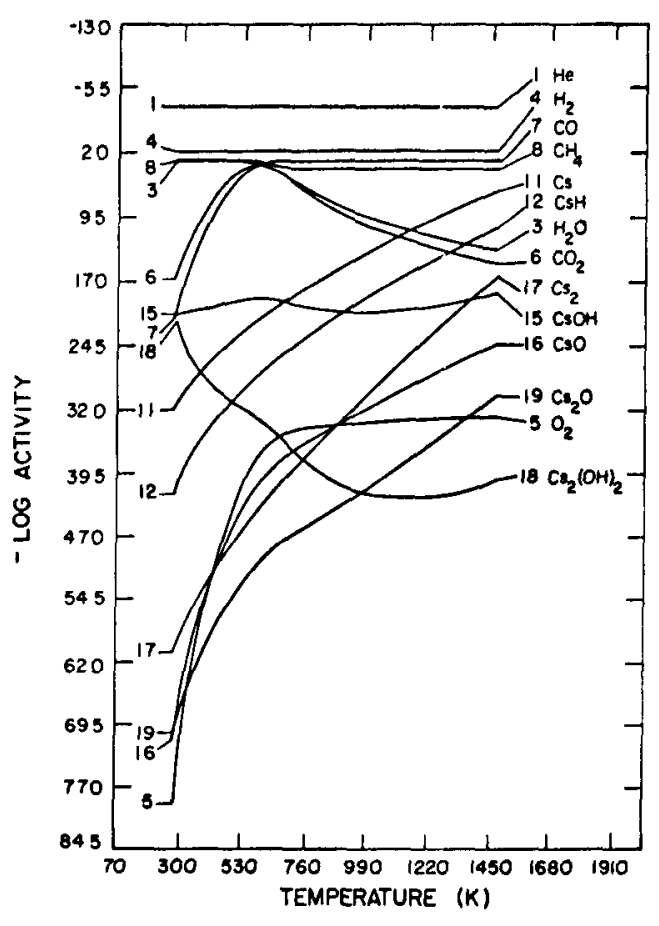

Fig. 33.

Distribution of species in the Peach Bottom stoichiometry at $2296 \mathrm{kPa}$. No excess carbon present for gas reactions. Cesium present as a $0.01 \%$ isotherm. 


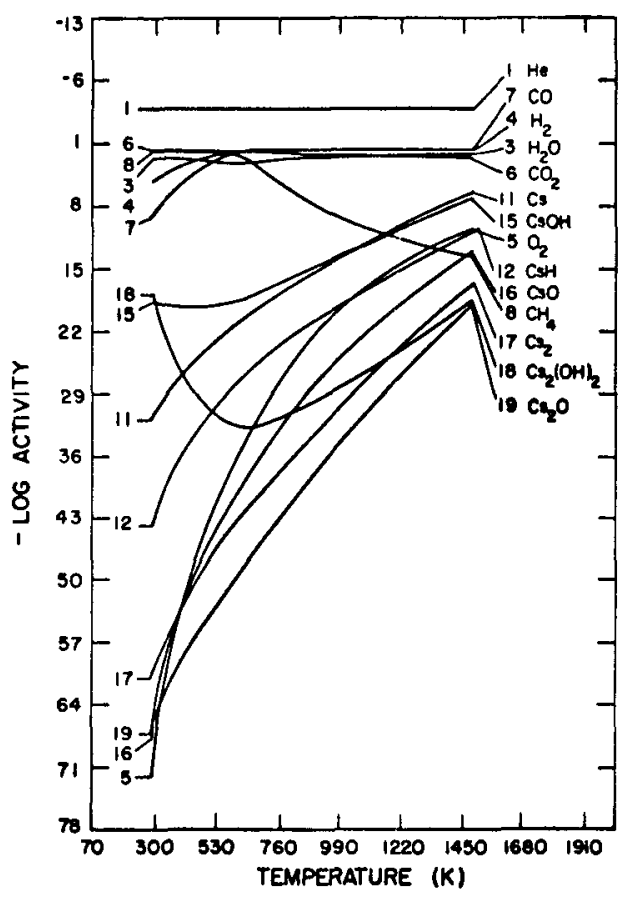

Fig. 34.

Distribution of species in the AVR stoichiometry at $965 \mathrm{kPa}$. No excess carbon present for gas reactions. Cesium present as a $0.01 \%$ isotherm.

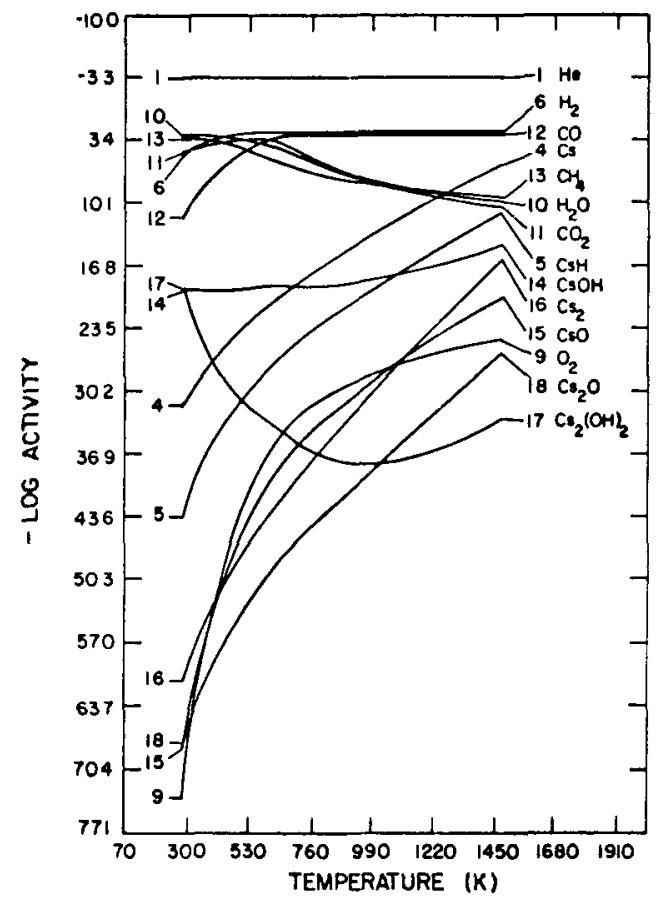

Fig. 36.

Distribution of species in the Dragon stoichiometry at $2068 \mathrm{kPa}$. Excess carbon present. Cesium present as a $0.01 \%$ isotherm.

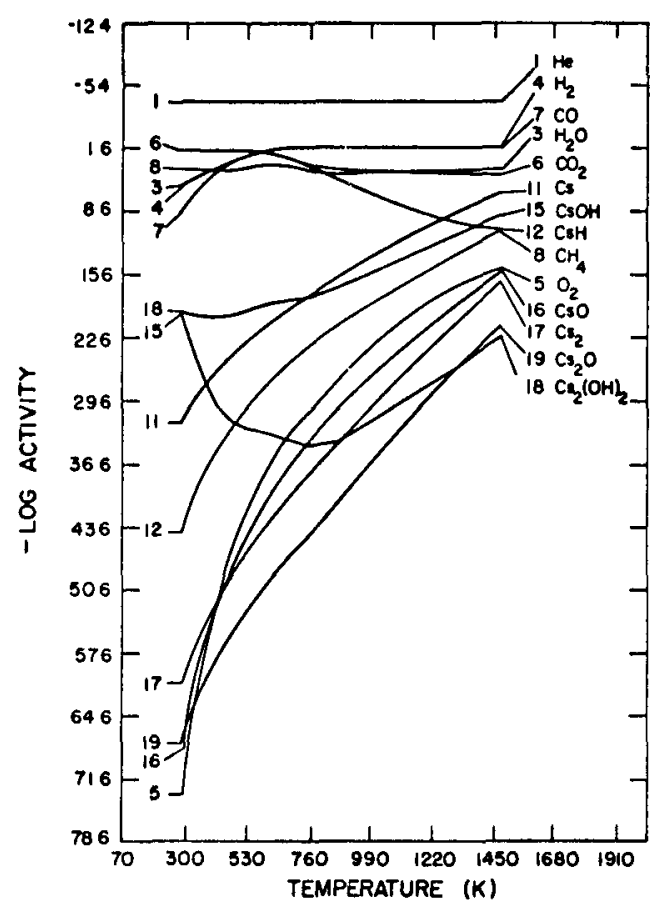

Fig. 35.

Distribution of species in Stoichiometry $I$ at $5050 \mathrm{kPa}$. No excess carbon present for gas reactions. Cesium present as a $0.01 \%$ isotherm.

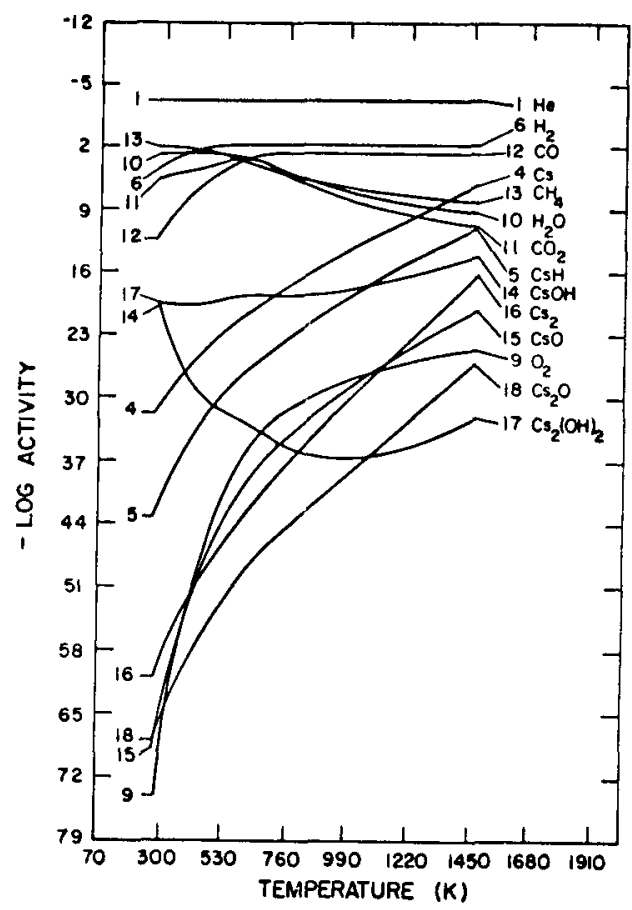

Fig. 37.

Distribution of species in the Peach Bottom stoichiometry at $2296 \mathrm{kPa}$. Excess carbon present. Cesium present as a $0.01 \%$ isotherm. 


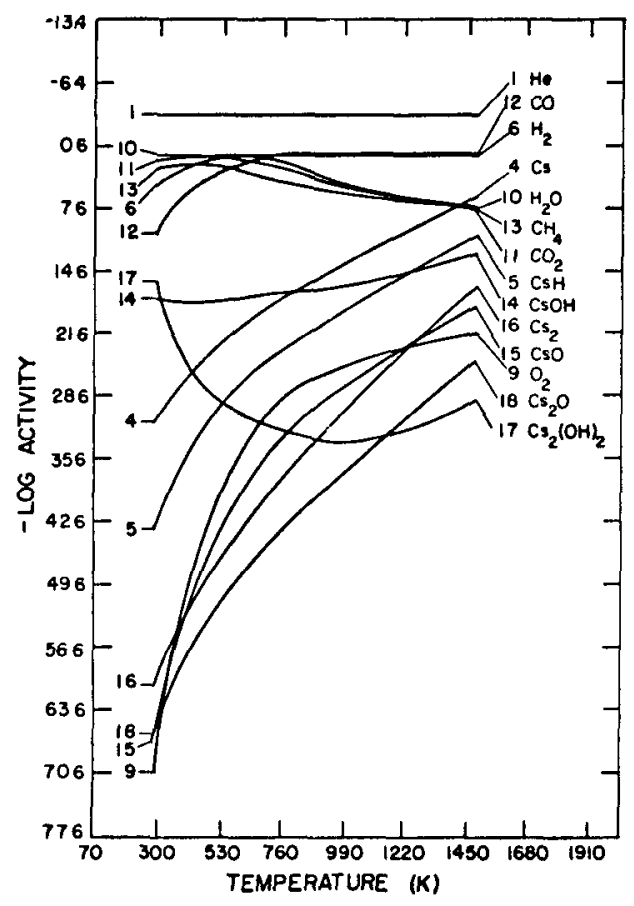

Fig. 38.

Distribution of species in the AVR stoichiometry at $965 \mathrm{kPa}$. Excess carbon present. Cesium present as a $0.01 \%$ isotherm.

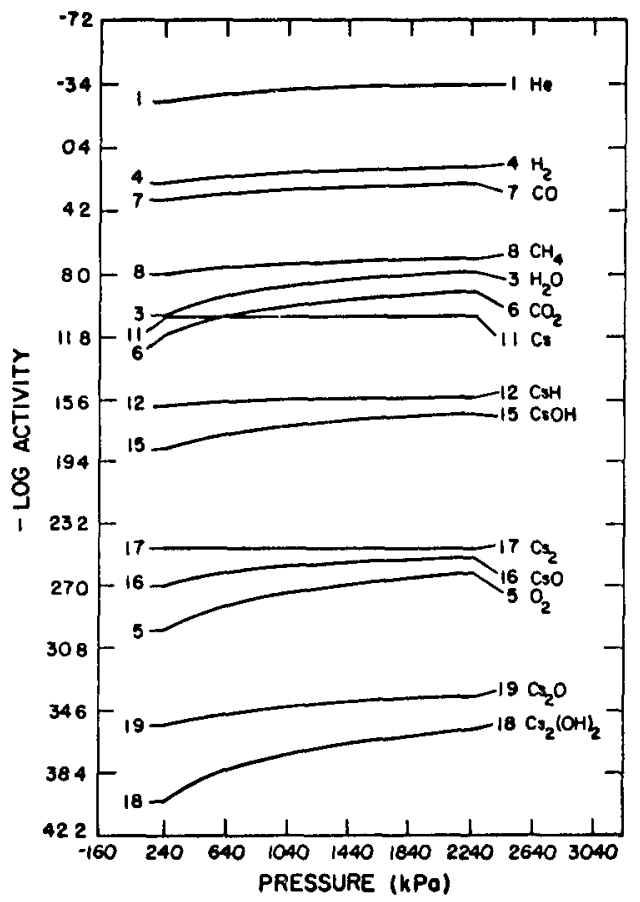

Fig. 40.

Distribution of species in the Peach Bottom stoichiometry equilibrated at $1200 \mathrm{~K}$ with excess carbon at $2296 \mathrm{kPa}$. No excess carbon present during depressurization. Cesium present as a $0.01 \%$ isotherm.

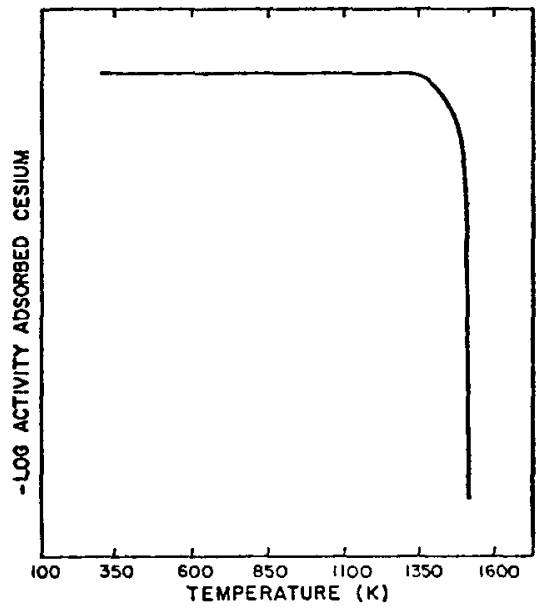

Fig. 39.

Schematic activity of adsorbed cesium in a typical reactor environment. Cesium present at $0.01 \%$ of monolayer coverage. Variations in the absence of carbon are in the range of parts per thousand. Variations in the presence of carbon are in the range of parts per million. Activity taken as the fraction of monolayer coverage.

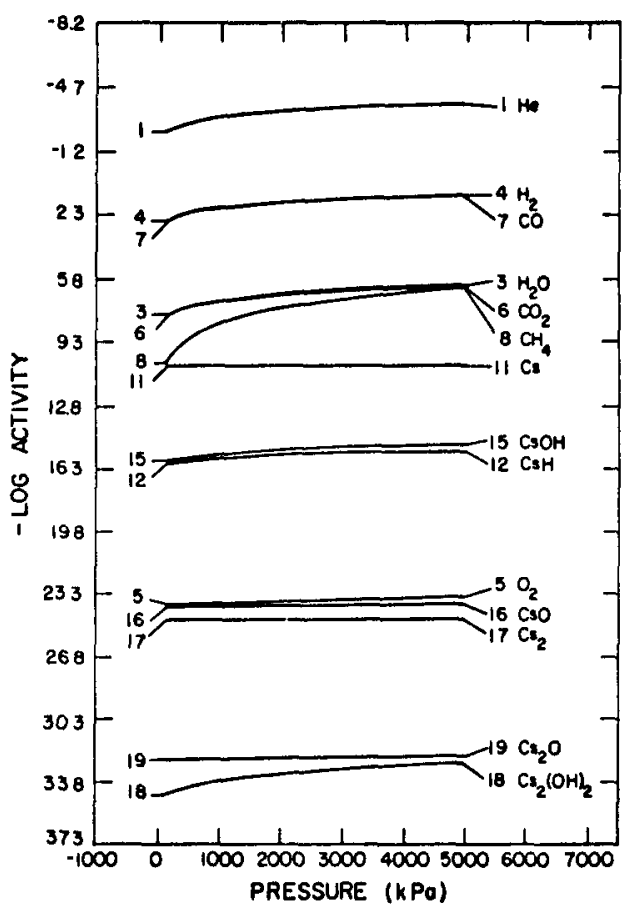

Fig. 41.

Distribution of species in Stoichiometry $I$ equilibrated at $1200 \mathrm{~K}$ with excess carbon at $5050 \mathrm{kPa}$. No excess carbon present during depressurization. Cesium present as a $0.01 \%$ isotherm. 


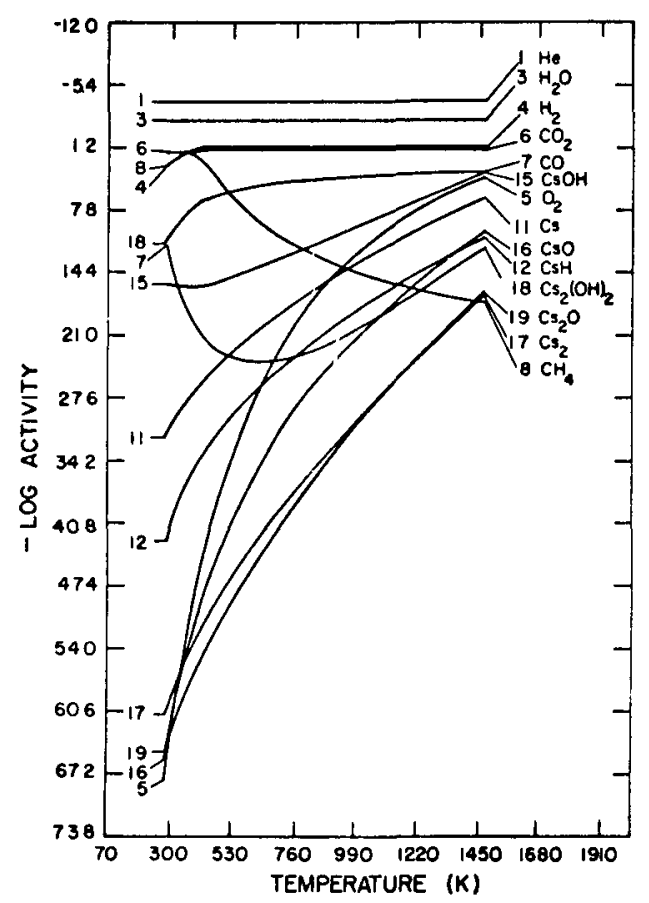

Fig. 42.

Distribution of species in Stoichiometry I with $10000 \mathrm{ppm} \mathrm{H}_{2} \mathrm{O}$ at $5050 \mathrm{kPa}$. No excess carbon present. Cesium present as a $0.01 \%$ isotherm.

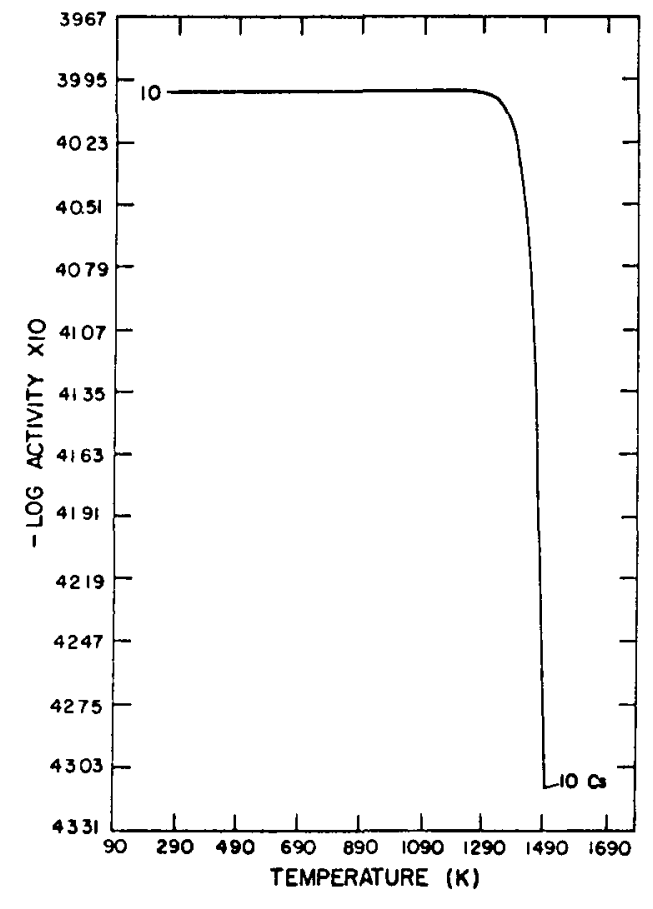

Fig. 43.

Activity of a $0.01 \%$ cesium isotherm in Stoichiometry I with $10000 \mathrm{ppm} \mathrm{H}_{2} \mathrm{O}$ at 5050 $k P a$. No excess carbon present. Activity taken as the fraction of monolayer coverage. 


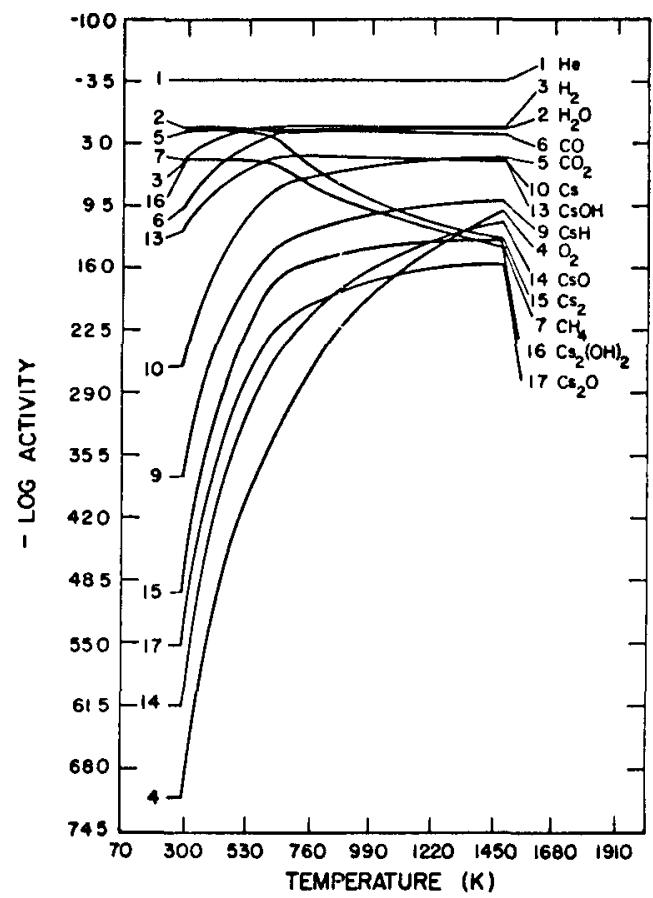

Fig. 44.

Distribution of species in Stoichiometry I with $10 \mathrm{ppm} \mathrm{H}_{2} \mathrm{O}$ at $5050 \mathrm{kPa}$. No excess carbon present. Cesium present at $10^{-8} \mathrm{v} / \mathrm{v}$ gaseous.

kinetics of gas diffusion. In other words, the cesium pressure above the surface will be maintained by the cesium adsorbed on the surface, the $\mathrm{CsOH} / \mathrm{Cs}$ ratio will be high, and any mechanism that transports gas out of the core will be enhanced by the ratio of $\mathrm{CsOH} / \mathrm{Cs}$.

\section{ACCIDENT CONDITIONS}

Thermal transients above $1500 \mathrm{~K}$ are sufficient to cause significant equilibrium transport of fission-product cesium from the core to the coolant gases. If large quantities of cesium were dumped into the coolant, the equilibria distributions calculated for lower cesium impurity levels would not be much changed. To illustrate, Fig. 44 presents a calculation of Stoichiometry I with $10 \mathrm{ppm} \mathrm{H}_{2} \mathrm{O}$ and cesium added as $10^{-8} \mathrm{v} / \mathrm{v}$ gaseous. Although the absolute level of cesium is 8 orders of magnitude higher in this distribution, the appearance of the three regimes is unaltered. The addition of only $10 \mathrm{ppm}_{2} \mathrm{O}$ has moved the $\mathrm{CsOH} / \mathrm{Cs}$ transition temperature above $1200 \mathrm{~K}$ and caused the equilibrium ratio of $\mathrm{CsOH} / \mathrm{Cs}$ to increase sharply.

\section{SUMMARY}

The equilibrium analysis of cesium in an HTGR suggests two mechanisms by which cesium transport from the core to the coolant could become important.

The first mechanism is a direct one in which cesium is transported from the core to the coolant as elemental cesium by thermal transients above $1500 \mathrm{~K}$. The isotherms of cesium simply become unstable in the HTGR environment above this temperature. 
The second mechanism is an indirect one in which cesium is transported from the core to the coolant as the monomeric hydroxide as a result of chemical transients-in this case, steam ingress. The adsorbed cesium is stable under all conditions of steam ingress considered, but such transients produce high $\mathrm{CsOH} / \mathrm{Cs}$ ratios. Transverse flow and/or gaseous diffusion out of the core would then be enhanced by such a high ratio.

\section{REFERENCES}

1. W. A. Stark, Jr., and R. C. Feber, "Multicomponent Analysis of the Carbon/Water Equilibria in the HTGR Primary Coolant System," Los Alamos Scientific Laboratory report LAMS-NUREG-6231 (April 1976).

2. F. van Zeggeren and S. H. Storey, The Computation of Chemical Equilibria (Cambridge Univ. Press, 1970).

3. E. E. Osborne, "Smallest Least Squares Solutions of Linear Equations," SIAM J. Numer. Anal. Ser. B, 2, 300-307 (1965).

4. K. Levenberg, "A Method for the Solution of Certain Non-Linear Problems in Least Squares," Q. Appl. Math. 2, 164-168 (1944).

5. D. W. Marquardt, "An Algorithm for Least-Squares Estimation of Nonlinear Parameters," J. Soc. Indust. Appl. Math. 11, 431-441 (1963).

6. S. Glasstone, "Free Energy and Chemical Reactions," in Thermodynamics for Chemists (van Nostrand, New York, 1947), pp. 273-316.

7. D. O. Hayward and B. M. W. Trapnell, Chemisorption, 2nd ed. (Butterworths, Washington, DC, 1964).

8. "Public Service Company of Colorado 330-MW(E) High-Temperature Gas-Cooled Reactor Research and Development Program Quarterly Progress Report for the Period Ending December 31, 1965," General Atomic report GA-6950 (March 1966).

9. "HTGR Base Program Quarterly Progress Report for the Period Ending May 31, 1968," Gulf General Atomic report GA-8662 (June 1968).

10. "HTGR Base Program Quarterly Progress Report for the Period Ending November 30, 1970," Gulf General Atomic report GA-10399 (December 1970).

11. "HTGR Base Program Quarterly Progress Report for the Period Ending February 28, 1971," Gulf General Atomic report GA-10501 (March 1971).

12. "HTGR Base Program Quarterly Progress Report for the Period Ending May 31, 1971," Gulf General Atomic report GA-10661 (June 1971).

13. "HTGR Base Program Quarterly Progress Report for the period Ending May 31, 1974," General Atomic Co. report GA-A13030 (June 1974).

14. "HTGR Base Program Quarterly Progress Report for the Period Ending August 31, 1967," General Atomic report GA-8200 (September 1967). 
15. C. E. Milstead, "Sorption Characteristics of the Cesium-Graphite System at Elevated Temperatures and Low Cesium Pressures," Carbon 7, 199-200 (1969).

16. C. E. Milstead, A. B. Riedinger, and L. R. Zumwalt, "Cesium-Graphite Sorption Isotherms Determined by a Static Method," Carbon 4, 99-106 (1966).

17. E. E. Anderson, G. L. Wessman , and L. R. Zumwalt, "Fission Product Trapping-Sorption of Cesium by Activated Charcoal," Nucl. Sci. Eng. 12, 106-110 (1962).

18. "HTGR Base Program Quarterly Progress Report for the Period Ending February 28, 1974," General Atomic Co. report GA-A12916 (March 1974).

19. T. D. Pyecha and L. R. Zumwalt, "Sorption of Cesium by Graphites as a Function of Strontium and Barium Concentration at High Temperatures. Progress Report for the Period May 1, 1974-January 31, 1975," North Carolina State Univ. report.

20. M. K. Yates and G. O. Fitzpatrick, "Cesium Sorption in Materials for Thermionic Converters," Gulf General Atomic report GA-8574 (Part II) (April 1970).

21. G. F. De Beni, O. Gautsch, and H. Wahl, "Some Experimental Results on the Sorption of Cesium by Tungsten and Graphite," Joint Nuclear Research Center, Ispra, Italy, report EUR-4549 e (July 1970).

22. M. K. Yates and G. O. Fitzpatrick, "Cesium Sorption for Integral Reservoirs," Gulf General Atomic report GA-8771 (October 1968).

23. "Public Service Company of Colorado 330-MW(E) High-Temperature Gas-Cooled Reactor Research and Development Program Quarterly Progress Report for the Period Ending September 30, 1965," General Atomic report GA-6830 (December 1965).

24. J. Board, "The Effect of a Helium Environment on the High Temperature Properties of Structural Materials," J. Br. Nucl. Energy Soc. 9, 101 (1970).

25. "HTGR Base Program Monthly Report for the Period Ending May, 1975," Oak Ridge National Laboratory report.

it U.S. GOVERNMENT PRINTING OFFICE: 1976-777-018/15 